Atmos. Chem. Phys., 17, 10893-10918, 2017

https://doi.org/10.5194/acp-17-10893-2017

(C) Author(s) 2017. This work is distributed under

the Creative Commons Attribution 3.0 License.

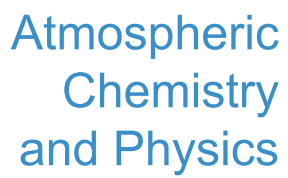

(c) (P)

\title{
A meteorological and chemical overview of the DACCIWA field campaign in West Africa in June-July 2016
}

\author{
Peter Knippertz ${ }^{1}$, Andreas H. Fink ${ }^{1}$, Adrien Deroubaix ${ }^{2}$, Eleanor Morris ${ }^{3}$, Flore Tocquer ${ }^{4}$, Mat J. Evans ${ }^{3}$, \\ Cyrille Flamant $^{5}$, Marco Gaetani ${ }^{5}$, Christophe Lavaysse ${ }^{6}$, Celine Mari ${ }^{4}$, John H. Marsham ${ }^{7}$, Rémi Meynadier $^{8}$, \\ Abalo Affo-Dogo ${ }^{9}$, Titike Bahaga ${ }^{1}$, Fabien Brosse ${ }^{4}$, Konrad Deetz $^{1}$, Ridha Guebsi ${ }^{5}$, Issaou Latifou ${ }^{9}$, \\ Marlon Maranan ${ }^{1}$, Philip D. Rosenberg ${ }^{7}$, and Andreas Schlueter ${ }^{1}$ \\ ${ }^{1}$ Institute of Meteorology and Climate Research, Karlsruhe Institute of Technology, 76128 Karlsruhe, Germany \\ ${ }^{2}$ Laboratoire de Météorologie Dynamique, Ecole Polytechnique, IPSL Research University, Ecole Normale Supérieure, \\ Université Paris-Saclay, Sorbonne Universités, UPMC Univ Paris 06, CNRS, 91128 Palaiseau, France \\ ${ }^{3}$ Wolfson Atmospheric Chemistry Laboratories, Department of Chemistry, University of York, York, YO10 5DD, UK \\ ${ }^{4}$ Laboratoire d'Aérologie, Université de Toulouse, CNRS, UPS, 31400 Toulouse, France \\ ${ }^{5}$ LATMOS/IPSL, Sorbonne Universités, UPMC Univ Paris 06, UVSQ, CNRS, 75252 Paris, France \\ ${ }^{6}$ European Commission, Joint Research Centre, Ispra (VA), Italy \\ ${ }^{7}$ School of Earth \& Environment/National Centre for Atmospheric Science, University of Leeds, Leeds LS2 9JT, UK \\ ${ }^{8}$ AXA Group Risk Management Department, Paris, France \\ ${ }^{9}$ Direction Générale Météo Nationale, B.P. 1505, Lomé, Togo
}

Correspondence to: Peter Knippertz (peter.knippertz@kit.edu)

Received: 13 April 2017 - Discussion started: 4 May 2017

Revised: 26 July 2017 - Accepted: 31 July 2017 - Published: 14 September 2017

\begin{abstract}
In June and July 2016 the Dynamics-AerosolChemistry-Cloud Interactions in West Africa (DACCIWA) project organised a major international field campaign in southern West Africa (SWA) including measurements from three inland ground supersites, urban sites in Cotonou and Abidjan, radiosondes, and three research aircraft. A significant range of different weather situations were encountered during this period, including the monsoon onset. The purpose of this paper is to characterise the large-scale setting for the campaign as well as synoptic and mesoscale weather systems affecting the study region in the light of existing conceptual ideas, mainly using objective and subjective identification algorithms based on (re-)analysis and satellite products. In addition, it is shown how the described synoptic variations influence the atmospheric composition over SWA through advection of mineral dust, biomass burning and urban pollution plumes.

The boreal summer of 2016 was characterised by Pacific La Niña, Atlantic El Niño and warm eastern Mediterranean conditions, whose competing influences on precipitation led to an overall average rainy season. During the relatively
\end{abstract}

dusty pre-onset Phase 1 (1-21 June 2016), three westwardpropagating coherent cyclonic vortices between 4 and $13^{\circ} \mathrm{N}$ modulated winds and rainfall in the Guinea coastal area. The monsoon onset occurred in connection with a marked extratropical trough and cold surge over northern Africa, leading to a breakdown of the Saharan heat low and African easterly jet and a suppression of rainfall. During this period, quasistationary low-level vortices associated with the trough transformed into more tropical, propagating disturbances resembling an African easterly wave (AEW). To the east of this system, moist southerlies penetrated deep into the continent. The post-onset Phase 2 (22 June-20 July 2016) was characterised by a significant increase in low-level cloudiness, unusually dry conditions and strong northeastward dispersion of urban pollution plumes in SWA as well as rainfall modulation by westward-propagating AEWs in the Sahel. Around 12-14 July 2016 an interesting and so-far undocumented cyclonic-anticyclonic vortex couplet crossed SWA. The anticyclonic centre had its origin in the Southern Hemisphere and transported unusually dry air filled with aged aerosol into the region. During Phase 3 (21-26 July 2016), a 
similar vortex couplet slightly farther north created enhanced westerly moisture transports into SWA and extraordinarily wet conditions, accompanied by a deep penetration of the biomass burning plume from central Africa. Finally, a return to more undisturbed monsoon conditions took place during Phase 4 (27-31 July 2016). The in-depth synoptic analysis reveals that several significant weather systems during the DACCIWA campaign cannot be attributed unequivocally to any of the tropical waves and disturbances described in the literature and thus deserve further study.

\section{Introduction}

The atmosphere over summertime West Africa is influenced by processes covering a wide range of scales, which can interact with each other in complex ways (Lafore et al., 2010; Redelsperger et al., 2006). The dominating phenomenon is the West African monsoon (WAM), which is mainly driven by the surface pressure contrast between the relatively cool waters of the eastern tropical Atlantic Ocean and the Saharan heat low (SHL). The former is related to the installation of the Atlantic cold tongue (ACT) starting in April-May and reaching its maximum horizontal extension in mid-August (Caniaux et al., 2011). At the Equator, colder sea surface temperatures (SSTs) increase the stability of the marine atmospheric boundary layer and decrease the vertical mixing of momentum, leading to weaker surface southerlies (Wallace et al., 1989), while north of the Equator as far as the Guinea coast, the large meridional SST gradient strengthens the surface wind through a hydrostatically induced meridional pressure gradient (Lindzen and Nigam, 1987). This creates a low-level circulation characterised by surface wind divergence and subsidence over the Equator and convergence and convection close to the Guinea coast in the period before the full onset of the WAM.

The SHL is a lower tropospheric thermal depression in the Sahara desert west of $10^{\circ} \mathrm{E}$, which develops in response to the intense surface heating during boreal summer (Lavaysse et al., 2009). The monsoon typically sets in quite abruptly around the end of June accompanied by a shift in the area of main rainfall from the Guinea coast to the Sahel (Fitzpatrick et al., 2015; Sultan and Janicot, 2003). This event is usually preceded by a northward shift in the so-called intertropical discontinuity (ITD), the near-surface confluence zone between southwesterly and northeasterly winds, which marks a northern limit of rainfall occurrence (Fitzpatrick et al., 2016; Lélé and Lamb, 2010). After the monsoon onset, the midtropospheric circulation over West Africa is dominated by the African easterly jet (AEJ), which is caused by the strong meridional temperature and moisture gradient at low levels (Cook, 1999; Wu et al., 2009). The AEJ is maintained by the anticyclonic circulation associated with the monsoonal subsidence, which characterises the mid-upper troposphere over the Sahara (Chen, 2005; Thorncroft and Blackburn, 1999) and above the shallow dry convection in the SHL (GarciaCarreras et al., 2015; Ryder et al., 2015). Barotropic and baroclinic instabilities associated with the jet create an environment favourable to the generation of African easterly waves (AEWs) (Thorncroft and Hoskins, 1994a, b; Wu et al., 2012), synoptic-scale disturbances characterised by a $2-$ 6-day period in the Sahel. Diedhiou et al. (1999) present evidence for a more intermittent, slower (6-9-day period) wave regime with cyclonic and anticyclonic centres straddling the AEJ, longer wavelengths and an activity maximum over the continent in June and July.

On multi-decadal to inter-annual timescales, WAM variability is strongly associated with global SST anomalies (Rodríguez-Fonseca et al., 2015; Rowell, 2013). For example, positive phases of the Atlantic multi-decadal variability favour precipitation in the Sahel (Ting et al., 2011; Zhang and Delworth, 2006). On inter-annual timescales, SST variability in the tropical Atlantic modulates the land-sea thermal gradient, leading to meridional displacements of the precipitation belt over West Africa (Losada et al., 2010; Polo et al., 2008). SSTs over the Mediterranean Sea influence the amount of moisture being transported across the Sahara desert and converging over the eastern Sahel (Fontaine et al., 2010; Gaetani et al., 2010). Inter-annual variability in the WAM is also influenced by the SST variability in the tropical Indian and Pacific oceans, which may trigger stationary waves along the Equator interacting over the Sahel (Mohino et al., 2011; Rowell, 2001).

On intra-seasonal to synoptic timescales, an important source of variability is the propagation of convectively coupled equatorial wave (CCEW) disturbances and the MaddenJulian oscillation (MJO) (Mohino et al., 2012; Pohl et al., 2009). In addition, variability in the SHL strength and position modulate the distribution of the monsoonal precipitation in the Sahel in the zonal direction. During periods of a deeper SHL, the shallow cyclonic circulation associated with the thermal low is intensified, strengthening the Atlantic westerly flow and the convergence in the Sahel, which leads to wet (dry) anomalies in the eastern (western) Sahel (Lavaysse et al., 2010b). The SHL phases are modulated on synoptic timescales by both tropical and midlatitude disturbances (Chauvin et al., 2010; Lavaysse et al., 2010a). Other types of intra-seasonal variability include the Sahelian and quasi-biweekly zonal dipole (QBZD) modes on timescales of 10-25 days (Janicot et al., 2011; Mounier et al., 2008; Roehrig et al., 2011). Variations in the intensity and position of the AEJ influence the location, amplitude and propagation speed of AEWs, which play a crucial role in the modulation of convective precipitation in the Sahel, mainly through their influence on thermodynamics and vertical wind shear (Gu et al., 2004; Skinner and Diffenbaugh, 2013). To the south of the Sahel, low-level vortices unrelated to AEWs can affect rainfall (e.g. Fink et al., 2006). Convection in West Africa is often organised on the mesoscale, particularly in the form of 
fast-propagating squall line systems (Fink and Reiner, 2003), but more isolated thunderstorms or showers also occur, e.g. triggered by the sea-breeze convergence along the Guinea coast (Fink et al., 2010). The moist convection embedded within the monsoon flow has been shown to be intrinsic to the monsoon, and the poor representation of convection in models leads to biases in the WAM (Birch et al., 2014; GarciaCarreras et al., 2013; Marsham et al., 2013).

The atmospheric composition over southern West Africa (SWA hereafter) during the wet season is a complex combination of air masses transported from remote sources, bringing desert dust or biomass burning aerosol, and local anthropogenic pollution (Mari et al., 2011). The Sahara desert to the north of the region is the largest aerosol source in the world and the transport of dust southwards is a significant source of aerosol for SWA (e.g. Chiapello, 2014; Shao et al., 2011). Forest fires in the immediate region are not thought to be significant in this period, but the transport of biomass burning species from the Southern Hemisphere ( $\mathrm{SH}$ ) has been observed (Mari et al., 2008). Anthropogenic emissions from the combustion of fossil fuels, biofuels and refuse are on the rise and expected to keep increasing significantly in the near future due to the rapid growth of cities in the region (Knippertz et al., 2015b; Liousse et al., 2014). Air quality is thus a concern, with multiple sources of anthropogenic emissions from domestic open fires, road traffic, street dust, waste burning, oil extraction and refining, ships, industrial activity, power plants, etc. SWA is also characterized by a south-north gradient of vegetation, from rainforest in the coastal belt to the sub-Sahelian savannah in the north. The dense vegetation can emit large quantities of biogenic compounds (isoprene, monoterpenes, etc.), which profoundly alter the gas and aerosol composition in the region (Mari et al., 2011). The relative role of local biogenic and anthropogenic emissions, the long-range transport of other compounds into the SWA atmosphere, coupled to the peculiar dynamics of the region during the monsoonal period leads to a chemically complex region.

A lack of an observational network adequate to better understand processes and to evaluate model simulations and satellite data has impeded scientific progress in West Africa for a long time and motivated the organisation of large international field campaigns. An early example, which revolutionised the understanding of the WAM system at that time, is the Global Atmospheric Research Program (GARP) Atlantic Tropical Experiment (GATE) (Kuettner, 1974). The largest such programme in recent decades is the African Monsoon Multidisciplinary Analysis (AMMA), which took place in 2006 with a focus on Sahelian convection (Lebel et al., 2010). More recently, the Dynamics-AerosolChemistry-Cloud Interactions in West Africa (DACCIWA) project (Knippertz et al., 2015a) organised a major international field campaign during June and July 2016, focusing for the first time on the most populated southern coastal region of West Africa. In addition to a number of meteorolog- ical aspects, the DACCIWA campaign also had a focus on atmospheric composition, including questions of air pollution and cloud-aerosol interactions (Knippertz et al., 2015b). Field activities included measurements from three inland ground supersites (Savé in Benin, Kumasi in Ghana, Ile-Ife in Nigeria), urban sites (Cotonou in Benin, Abidjan in Côte d'Ivoire), radiosondes and three research aircraft stationed in Lomé (Togo). A detailed description of the field activities is given in Flamant et al. (2017).

The objectives of this paper are to (a) place the campaign period June-July 2016 into a larger-scale climatological context, (b) describe the behaviour of the WAM system (e.g. onset, AEJ and SHL positions), (c) characterise the most important synoptic-scale weather systems affecting SWA (e.g. AEWs, vortices), and (d) discuss impacts on rainfall, clouds and atmospheric composition. This way the paper aims to fulfil a similar role as Janicot et al. (2008) for AMMA. The analysis will build on and expand some of the concepts introduced in this section and provide a consistent framework for the detailed analysis of DACCIWA field campaign data in following years. From an atmospheric dynamics and chemistry perspective, SWA is of particular interest and has not been studied much in the past. AMMA had fewer stations in SWA and only a few publications covering this region. During GATE, data quality (e.g. from radiosondes and satellites) and data assimilation (e.g. use of cloud motion vectors) had not evolved enough to allow a reliable analysis of $850 \mathrm{hPa}$ streamlines for example, especially over the Gulf of Guinea (e.g. Sadler and Oda, 1979). Relying on the densest radiosonde network at the Guinea coast and in the Sudanian zone (Côte d'Ivoire, Ghana, Togo, Benin, Nigeria) ever, DACCIWA can for the first time provide a detailed account of SWA weather systems and their impacts on precipitation and atmospheric composition. In contrast to the Sahel, SWA is often characterised by situations with high moisture and relatively low convective inhibition (CIN), while the vertical wind shear is typically weak. Thus, convection is relatively easy to trigger and remains less well organised, yet brings substantial rains. These are often connected to weak and vertically shallow cyclonic and anticyclonic vortices (e.g. Fink et al., 2006), but details of this relationship are still unclear as is their linkage to classical equatorial wave and AEW disturbances. This paper will shed some new light on these fundamental unexplored dynamical features, including the specific question of onset dynamics.

The paper is structured as follows: in Sect. 2 an overview of the employed data and methods will be given. Section 3 contains a relatively short discussion of the large-scale settings followed by a more detailed analysis of the synopticscale evolution in Sect. 4. Section 5 discusses the implication of meteorological variation on atmospheric composition, focusing on Saharan and Sahelian dust, biomass burning aerosol from the $\mathrm{SH}$ and pollution plumes from the cities along the Guinea coast. Main conclusions will then be given in Sect. 6. 


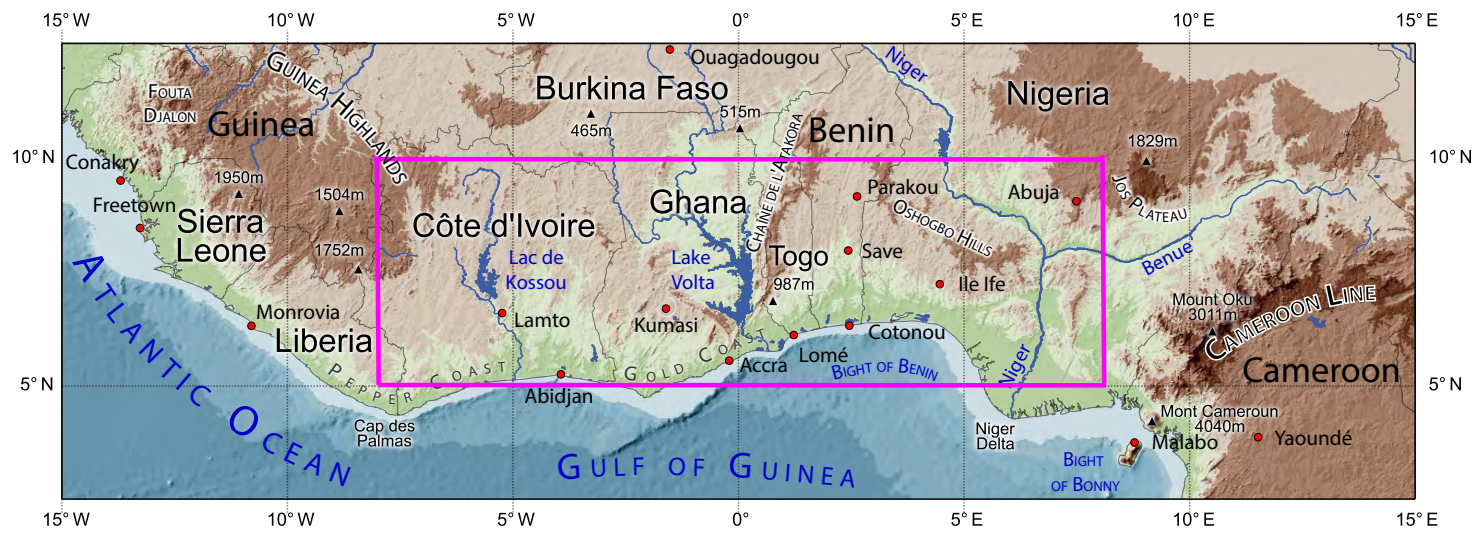

Figure 1. Geographical overview of the study region with sites and names. The purple rectangle marks the main DACCIWA focus region $\left(5-10^{\circ} \mathrm{N}, 8^{\circ} \mathrm{W}-8^{\circ} \mathrm{E}\right)$.

\section{Data and methods}

\subsection{Data}

For the investigation of atmospheric dynamics, analysis and reanalysis data from the European Centre for Medium-Range Weather Forecasts (ECMWF) are used. Most of the analyses are based on the ERA-Interim (hereafter ERA-I) reanalysis at about $0.7^{\circ}$ grid spacing (Dee et al., 2011), which allows the computation of background climatologies back to 1979. For investigations focusing on the campaign period in 2016 alone, the higher-resolution operational analyses (native resolution of $\sim 9 \mathrm{~km}$; model version Cy41r2; see www. ecmwf.int) are employed. As there was no change to the operational system during the study period, these data can be regarded as homogeneous, in contrast to longer time spans of operational data. The majority of radiosondes launched during the DACCIWA field campaign were distributed through the Global Telecommunication System and were assimilated at ECMWF. For the analysis of ocean influences on West Africa, the $0.25^{\circ}$ daily Reynolds Optimum Interpolation SST data are used. The dataset combines observations from different platforms (satellites, ships, buoys) on a regular global grid. A spatially complete SST map is produced by interpolating to fill in gaps (Reynolds et al., 2007). Data have been retrieved from the NOAA NCDC (National Oceanic and Atmospheric Administration - National Climatic Data Center) FTP site (http://www.ncdc.noaa.gov). Monthly anomalies for June-July 2016 and daily anomalies are based on the 19812016 climatology.

As a precipitation estimate, the standard Tropical Rainfall Measuring Mission (TRMM) product 3B42 (v7) with $0.25^{\circ}$ grid spacing is used (Huffman et al., 2007). This product combines information from space-borne radar and microwave and infrared channels, subject to monthly calibration with surface rain gauges if available. Since September 2014, the real-time calibration of microwave radiances using the precipitation radar has ceased due to the decommissioning of the TRMM satellite and was replaced by using climatological adjustments. Although this caused a discontinuity, the TRMM 3B42 product was prioritised over the Global Precipitation Measurement (GPM) Integrated Multi-satellite Retrievals for GPM (IMERG) successor product due to the longer availability (1998-2016), which allowed for the calculation of anomalies. The temporal resolution of this product is once every $3 \mathrm{~h}$, but here daily accumulations (22:3022:30 UTC) are used for most investigations. In addition, outgoing longwave radiation (OLR) data from the Spinning Enhanced Visible and Infrared Imager (SEVIRI) on the geostationary Meteosat Second Generation (MSG) satellites with a spatial and temporal resolution of $\sim 3 \mathrm{~km}$ at nadir and $15 \mathrm{~min}$, respectively, are used as a proxy for convective activity (Schmetz et al., 2002). In particular, channel 9 (i.e. approximately $9.80-11.80 \mu \mathrm{m}$ ) of the thermal infrared band is taken to retrieve cloud-top temperatures and to ensure day and night coverage. Different types of clouds are analysed using information on cloud-top characteristics (CTX) and the cloud mask (CMA) from the Satellite Application Facility on Climate Monitoring (CM SAF). Both the CTX and CMA subsets are part of the CLAAS-2 (Finkensieper et al., 2016) dataset, which is derived from information provided by SEVIRI (Stengel et al., 2013). Therefore, CLAAS data have the same temporal and spatial resolution as the SEVIRI dataset.

As this paper is meant to give a broad overview of meteorological and chemical conditions only, a detailed analysis of DACCIWA field campaign data is left to follow-up studies. The only exception is radiosonde data from Abidjan (for location, see Fig. 1) used to illustrate a period of unusual dryness during July 2016. Relative humidity was derived from (00:00, 06:00, 12:00 and 18:00 UTC) soundings four times daily using the high-resolution vertical profiles obtained from the MODEM radiosonde system. The analysis will concentrate on the main DACCIWA study region $\left(8^{\circ} \mathrm{W}-\right.$ 
$8^{\circ} \mathrm{E}, 5-10^{\circ} \mathrm{N}$, see Fig. 1), but influences on that region from a much wider area will be considered.

\subsection{Methods}

In order to better understand and characterise atmospheric variability during the DACCIWA campaign, a number of features important for SWA were objectively or subjectively identified:

1. Equatorial waves: the presence of CCEWs is identified using the wave filtering method in specific wavenumber-frequency domains as described in Wheeler and Kiladis (1999). In addition to the CCEWs (Kelvin waves, MJO, mixed Rossby-gravity and equatorial Rossby waves), tropical depression-like disturbances (TD) are filtered following the method by Roundy and Frank (2004). These often correspond to AEWs over West Africa. The filtering is applied to the 3-hourly TRMM 3B42 (v7) precipitation dataset (see Sect. 2.1) within the northern equatorial band $5-15^{\circ} \mathrm{N}$, which contains the bulk of the convective precipitation during the campaign period but excludes some heavier oceanic rainfalls (see Fig. 5b).

2. Heat low index: following Lavaysse et al. (2009), the low-level atmospheric thickness between 925 and $700 \mathrm{hPa}$ over a domain that covers northern and West Africa is used to determine the location and the intensity of the SHL. The location corresponds to the region with thickness values larger than the 90th percentile. The intensity is defined directly through the thickness in geopotential metres (gpm), indicating the thermal dilation of the lower atmosphere. Once the SHL is detected and the intensity of each grid point calculated, the centre of the SHL is defined as the barycentre in longitude and latitude, which is closely linked to the east and west phases of temperature anomalies proposed by Chauvin et al. (2010) when the SHL is located in its Saharan location (from end of June to mid-September). These computations are based on ERA-I (see Sect. 2.1).

3. AEJ index: average position and strength of the AEJ are objectively calculated based on Berry et al. (2007). Within the region $0-30^{\circ} \mathrm{N}$ and $8^{\circ} \mathrm{W}-8^{\circ} \mathrm{E}$ (longitudinal extent of DACCIWA focus region; see Fig. 1), 6-hourly ERA-I winds at $700 \mathrm{hPa}$ are used. A spatial low-pass filter with a cut-off wavelength of $1000 \mathrm{~km}$ is applied to calculate shear vorticity, which is then used to determine the jet axis. The average wind speed along the jet axis and the mean latitudinal position is estimated for JuneJuly 2016 and the long-term climatology (1987-2016) for comparison.

4. Mesoscale convective system (MCS) identification: the evolution of deep convective clouds is monitored by applying an overlap-based tracking algorithm (Mathon and Laurent, 2001; Schröder et al., 2009; Williams and Houze, 1987) to the $15 \mathrm{~min}$ infrared data of SEVIRI. In two successive images, cold cloud regions are identified first and then connected in time by determining the highest accordance with respect to area, area overlap and spatial translation. Here, deep convective clouds are defined as regions with a brightness temperature of $\leq 233 \mathrm{~K}$ and an area of least 100 contiguous pixels (i.e. $\sim 900 \mathrm{~km}^{2}$ ). The former criterion is widely used as a proxy for deep precipitating convection in tropical regions, whereas the latter excludes convective systems with low contribution to total cold cloud cover (Mathon and Laurent, 2001; Schröder et al., 2009).

5. Synoptic-scale vortices: close inspection of daily weather charts suggests that only a few classical AEWs occurred during the study period and that a more flexible approach is needed to fully represent the observed richness of coherent features. After some testing, a combination of subjective tracking of vortex centres from unfiltered $850 \mathrm{hPa}$ streamlines with Hovmöller plots of $850 \mathrm{hPa}$ vorticity and meridional wind was selected.

6. Long-range transport of biomass burning and dust enriched air masses: biomass burning plumes from central Africa transported into the domain were tracked with carbon monoxide (CO) calculated from the ECMWF Copernicus Atmosphere Monitoring Service-Integrated Forecasting System (CAMS-IFS; Inness et al., 2013). Dust plumes from Sahelian and Saharan sources, north of the DACCIWA domain, were identified using the CAMS-IFS dust aerosol optical depth (DAOD). Where available, CAMS-IFS assimilates satellite information to bring the model output closer to reality.

7. Turbulent dispersion of urban plumes from the five major cities, where DACCIWA aircraft and ground measurements were taken (Abidjan, Kumasi, Accra, Lomé, Cotonou; see Fig. 1), were calculated daily using forward trajectories of passive tracers in a Lagrangian framework. Two models were used: (a) FLEXPART v6.2 (https://www.flexpart.eu/; Stohl et al., 2005) driven with ECMWF ERA-I winds and (b) HYSPLIT v4.8 (Stein et al., 2015) driven by GDAS (Global Data Assimilation System) winds. Both models were run for $24 \mathrm{~h}$ with continuous emissions of the tracer. The extent of the plume was calculated in FLEXPART using the root mean square distance of particles from the source at the end of the $24 \mathrm{~h}$ simulation. For HYSPLIT the plume boundary was defined at the end of the $24 \mathrm{~h}$ at a threshold concentration of $10^{14} \mathrm{~m}^{-3}$, with one unit of tracer being emitted from the source in $24 \mathrm{~h}$. 


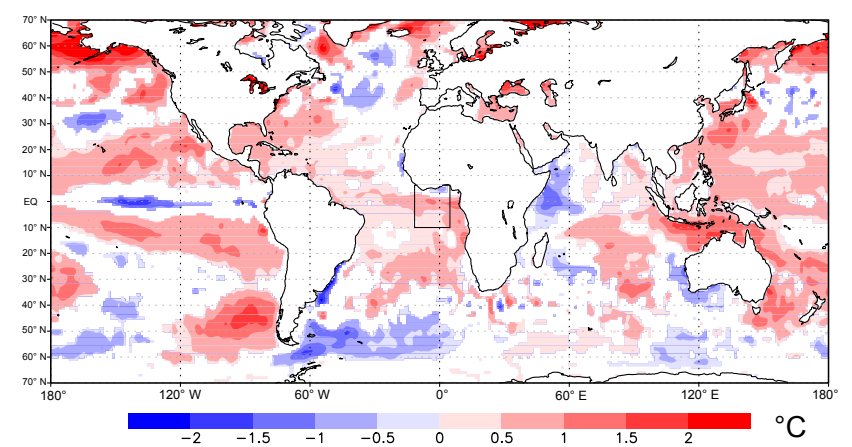

Figure 2. Global SST anomalies for June-July $2016\left({ }^{\circ} \mathrm{C}\right)$. Basis is the Reynolds Optimal Interpolated SST v2 dataset and anomalies are relative to 1981-2016. Only anomalies above the $95 \%$ confidence level based on a two-sided Student's $t$ test are plotted. The black box marks the area used for Fig. 3 .

\section{Large-scale settings}

This short section aims to characterise the large-scale setting the DACCIWA field campaign period, June-July 2016, was embedded in. Figure 2 shows global SST anomalies for June-July 2016. While at the beginning of the year El Niño conditions were still prevalent (not shown), by June a transition to La Niña had occurred, which usually favours monsoonal precipitation in the Sahel (Joly and Voldoire, 2009). At the same time, the equatorial Atlantic Ocean was relatively warm with widespread anomalies above $1 \mathrm{~K}$ (Fig. 2). These warm events, sometimes referred to as Atlantic El Niños (Okumura and Xie, 2006), are associated with a suppressed ACT and are linked with westerly surface wind perturbations at the Equator. The reduced surface wind stress causes less surface oceanic divergence and vertical mixing, leading to reduced SST cooling. This reduces the pressure gradient towards the SHL and thus the inland penetration of monsoonal rains. Since the 1970s, a frequent anticorrelation between El Niño in the Atlantic Ocean and El Niño in the Pacific Ocean has been observed (Rodríguez-Fonseca et al., 2015).

Warmer equatorial waters in the Gulf of Guinea as in 2016 exhibit a strong correlation with above-normal rainfall at the Guinea coast, which has been robust throughout the 20th century (Diatta and Fink, 2014). Mohino et al. (2011) argue that a warm eastern equatorial Atlantic Ocean and a simultaneous cold eastern Pacific Ocean exert compensational forcings on Sahelian rainfall, such that the archetypical dipole response during warm years in the Gulf of Guinea has rarely been observed after the 1970s. In the Mediterranean Sea, positive SST anomalies are found over the eastern basin accompanied by negative anomalies in the northwestern part of the Indian Ocean (Fig. 2). Positive SST differences between these two areas are associated with rainfall excess over the Sahel (Fontaine et al., 2011; Park et al., 2016). Overall, it appears that a combination of these different factors was in place in

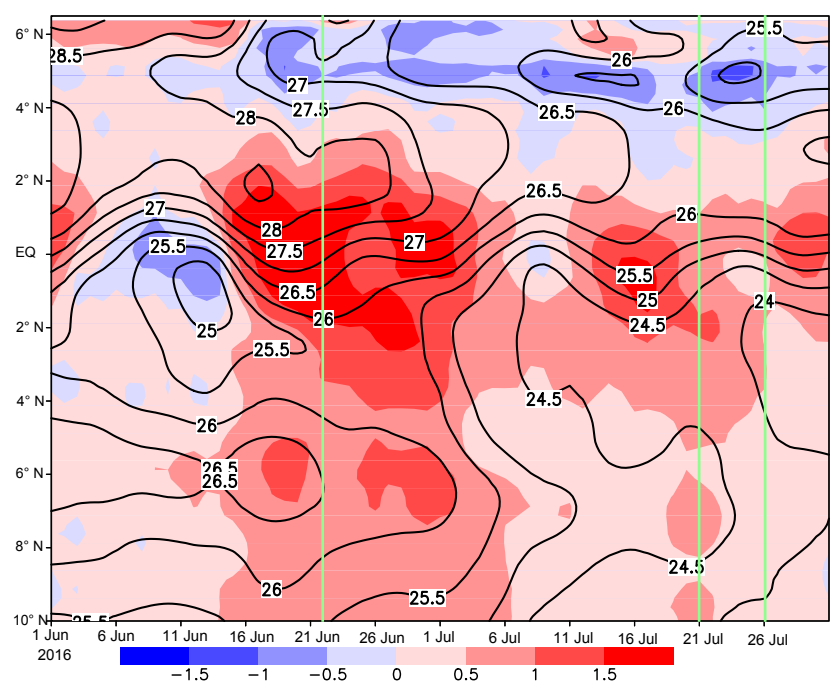

Figure 3. Daily SST behaviour over the eastern tropical Atlantic during June-July 2016. SSTs $\left({ }^{\circ} \mathrm{C}\right)$ are averaged between $10^{\circ} \mathrm{W}$ and $4^{\circ} \mathrm{E}$ (see box in Fig. 2) and shown as absolute values (lines) and anomalies (shading). Basis is the Reynolds Optimal Interpolated SST dataset and anomalies are relative to 1981-2016 as in Fig. 2. Only values greater than the SST Reynolds daily error estimation are plotted. The four phases of the DACCIWA campaign are marked with thin green lines.

2016 since the June-September Sahelian rainfall was only very slightly above normal (not shown). Standard indices indicate that the MJO was not active over West Africa in JuneJuly 2016 (not shown).

For the DACCIWA focus region (Fig. 1) and along most of the Guinea coast, June-September rainfall turned out to be normal (not shown), despite the extended dry spell during Phase 2 discussed in Sect. 4 (Fig. S1b in the Supplement). Only the Guinea and Cameroon line mountains and the Bight of Bonny had above-normal rainfall. It is unclear why the warmer waters in the Gulf of Guinea did not cause more rainfall in lowland areas. A possible explanation is warm SSTs in the South Atlantic (Fig. 2), which seem to reduce the positive effect of the equatorial Atlantic (Nnamchi and Li, 2011). In 2016, the situation was further complicated by relatively cold SSTs along the coasts of Senegal, Ghana and Togo, whose impacts on rainfall are not clear.

An inspection of the daily evolution of zonally averaged $\left(10^{\circ} \mathrm{W}-4^{\circ} \mathrm{E}\right) \mathrm{SST}$ s over the tropical eastern Atlantic during June-July 2016 reveals the typical establishment of the equatorial cold tongue $\left(1^{\circ} \mathrm{N}-5^{\circ} \mathrm{S}\right)$ and of upwelling of cooler water along the Guinea coast $\left(4-6^{\circ} \mathrm{N}\right)$ (Fig. 3). The onset of the ACT occurs around 10 June 2016 (mean date is 11 June with a standard deviation of 12 days according to Caniaux et al., 2011) with SSTs slightly below the long-term average, followed by a significant warming and southward retreat between mid-June and 5 July 2016, with warm anomalies surpassing $1.5 \mathrm{~K}$. After that, the ACT is re-established but abso- 
lute temperatures stay above average by $0.5 \mathrm{~K}$ or more until the end of July 2016, consistent with the anomalies shown in Fig. 2. The coastal upwelling sets in much later (Fig. 3). First indications of a cooling are found around 18 June 2016, but a more substantial cooling begins on 27 June 2016 until SSTs drop below $26^{\circ} \mathrm{C}$ across a broader coastal strip until the end of July. The phenomenon is a little stronger in 2016 than in other years, with negative anomalies of the order of $0.5 \mathrm{~K}$, particularly along $5^{\circ} \mathrm{N}$.

The other important driver of the WAM is the SHL. Figure 4 shows its intensity and position on a daily basis during June-July 2016. During the first 3 weeks of June, the SHL is in an intense phase (Fig. 4a) and shows large east-west fluctuations with a period of about 10 days, remaining mostly to the east of the climatological position (Fig. 4b). This shows some resemblance with the SHL variations described by Chauvin et al. (2010) but on rather short timescales. The SHL is also located further to the north than usual, associated with large positive temperature anomalies over northeastern Africa and anomalous southwesterly flow over the eastern Sahel (not shown). Around 20 June, the SHL abruptly weakens and shifts to a more southerly position, followed by a gradual intensification and northward retreat during the following week (Fig. 4a). It is still located east of its climatological position during this period (Fig. 4b). After that, a long strong phase begins to last until 18 July (Fig. 4a), during which the SHL gradually shifts westward (Fig. 4b) and also slightly northward. Around 18 July another abrupt weakening occurs and continues until the end of July 2016, only shortly interrupted by positive values (Fig. 4a). The SHL is located to the west of its climatological position during this time (Fig. 4b) and then migrates to the south at the end of July (Fig. 4a). In the next section, the impact of these fluctuations and those of SSTs on synoptic-scale variability over SWA will be discussed.

\section{Detailed synoptic analysis}

\subsection{General approach}

In order to guide the discussion of the DACCIWA field measurements, the study period is divided into distinctive phases and the most significant weather systems are labelled for better reference in other papers. The division into phases is mainly based on the north-south precipitation difference (NSPD hereafter) between the coastal zone $\left(0-7.5^{\circ} \mathrm{N}\right)$ and the Sudanian-Sahelian zone $\left(7.5-15^{\circ} \mathrm{N}\right)$, both averaged across the longitude range $8^{\circ} \mathrm{W}-8^{\circ} \mathrm{E}$ (see Fig. 6 for orientation). Figure 5a shows daily values of the NSPD based on TRMM precipitation estimates for June-July 2016. Figure $5 \mathrm{~b}$ shows the corresponding zonally averaged rainfall values against latitude. Four distinct phases are recognisable from this analysis.
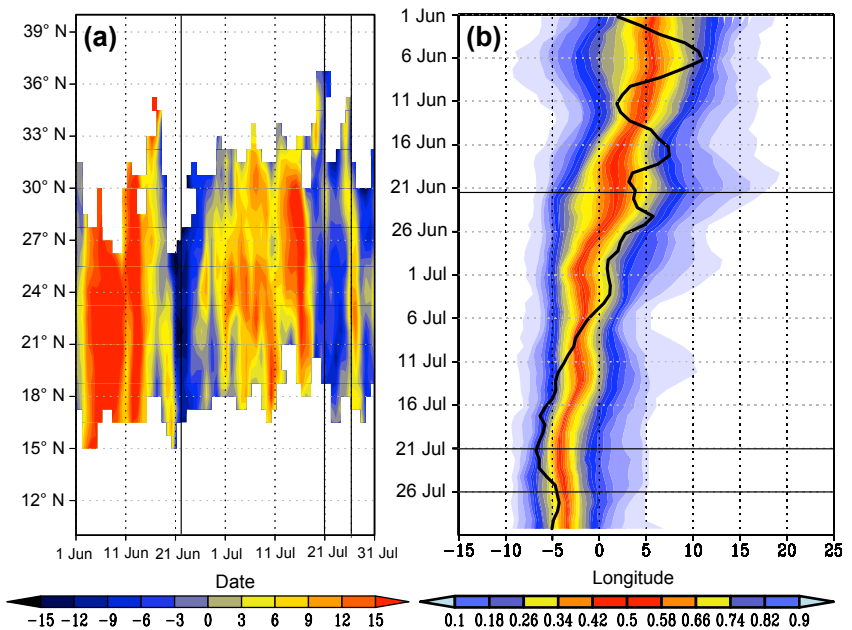

Figure 4. SHL evolution during June-July 2016. (a) Time-latitude anomalies of the SHL intensity (gpm) defined as the thickness between 925 and $700 \mathrm{hPa}$ (relative to 1979-2016). (b) Longitudinal location of the SHL barycentre (black line) with the 1979-2016 percentiles in colour shading. See Sect. 2.2 for more details. The four phases of the DACCIWA campaign are marked with thin black lines.

Phase 1 lasts from 1 to 21 June 2016 and is characterised by a rainfall maximum near the coast. However, it shows large fluctuations with periods around 5 days (Fig. 5a). Particularly the middle part of Phase 1 is very wet, while the earlier and later parts are characterised by more isolated rainfall peaks near $4^{\circ} \mathrm{N}$ (Fig. 5b). This modulation is consistent with the QBZD index, showing a significant minimum around 142016 (see http://misva.sedoo.fr). Rainfall during this period is unusually intense offshore of the Niger Delta area stretching across the Gulf of Guinea towards Cape Palmas (Fig. 6a; see also Fig. S1a for anomalies). A second rainfall maximum is located over the tropical Atlantic to the west of West Africa in Fig. 6a, where SSTs are climatologically much warmer (not shown). Precipitation does already stretch far inland into the Sahel but amounts are relatively low with the exception of the Cameroon line highland region along the border of Nigeria and Cameroon. The moderate changes from drier to wetter and back to drier conditions in the Sahel during Phase 1 are reflected in weak but hardly significant undulations of the intra-seasonal Sahelian index reaching a minimum on 12 June 2016 (see http://misva.sedoo.fr). The pre-monsoonal conditions are also reflected in fields of zonally averaged total column water vapour (TCWV) with values above $45 \mathrm{~mm}$ mostly restricted to south of $12^{\circ} \mathrm{N}$ (Fig. 7). The ITD (identified by the $14^{\circ} \mathrm{C}$ isoline of $2 \mathrm{~m}$ dew point) fluctuates around $16^{\circ} \mathrm{N}$ (Fig. 7).

Phase 1 corresponds closely to the period of anomalously strong SHL that fluctuates from east to west discussed in Sect. 3 (see Fig. 4), while correspondence to SST behaviour in the Gulf of Guinea (Fig. 3) is less clear. It is interest- 


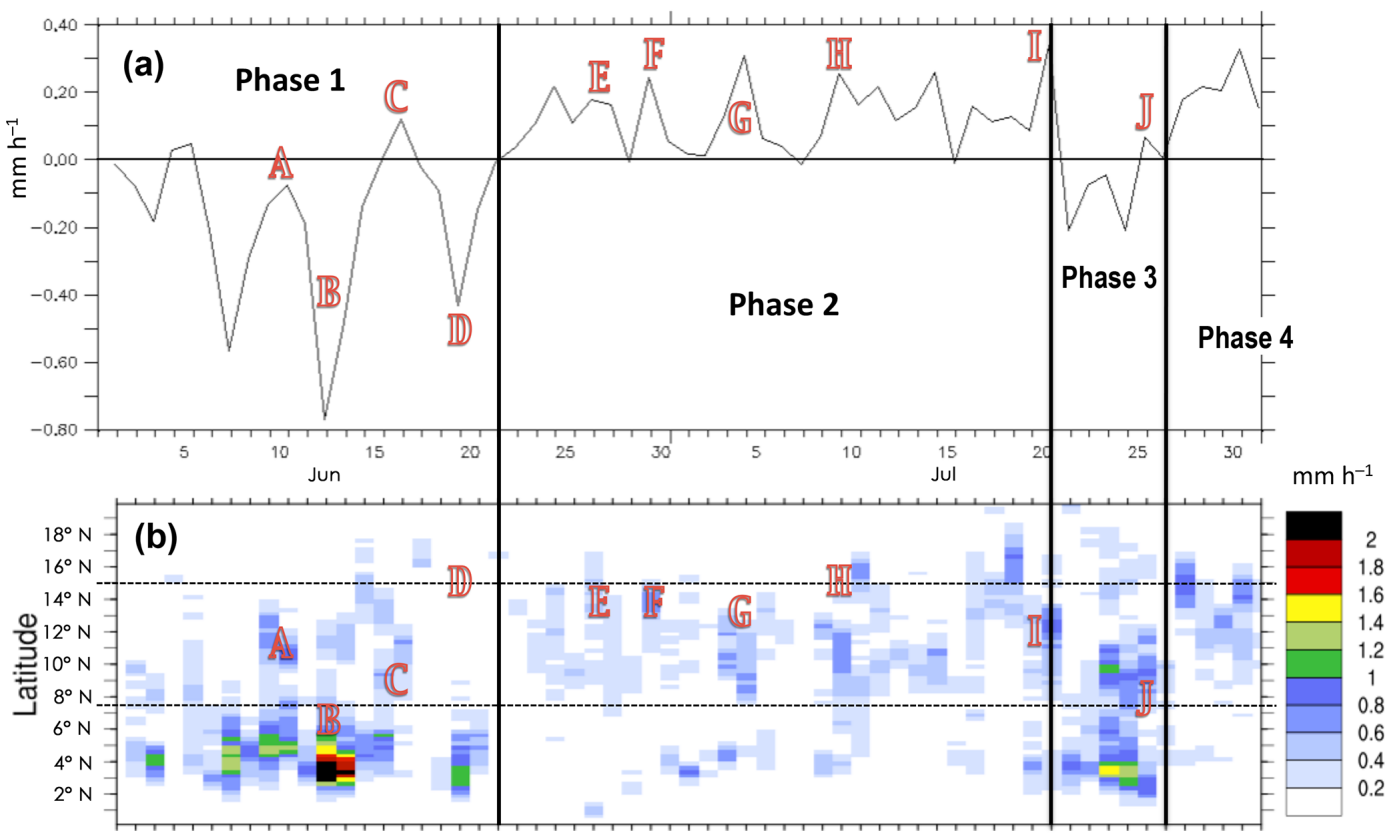

Figure 5. Rainfall evolution during June-July 2016. (a) North-south precipitation difference based on the 7.5-15 and 0-7.5 $\mathrm{N}$ bands (see boxes in Fig. 6). (b) Latitudinal distribution of rainfall. Both panels are based on daily TRMM precipitation values averaged over $8^{\circ}$ W$8^{\circ} \mathrm{E}$ (longitudes bordering DACCIWA focus region; see Fig. 1). The four phases of the DACCIWA campaign and significant synoptic-scale features A-J are marked at the approximate time (and also latitude in $\mathbf{b}$ ) of crossing the DACCIWA focus region.

(a) Phase 1

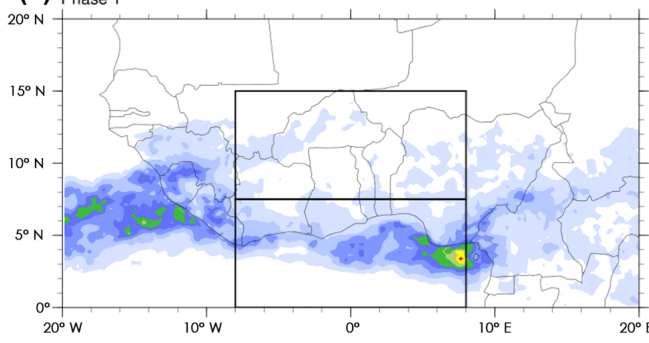

(c) Phase 3

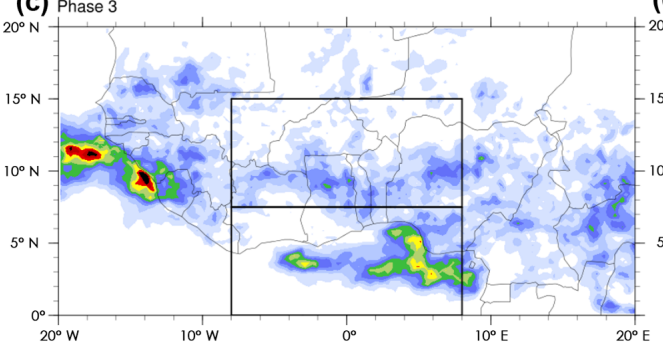

(b) Phase 2

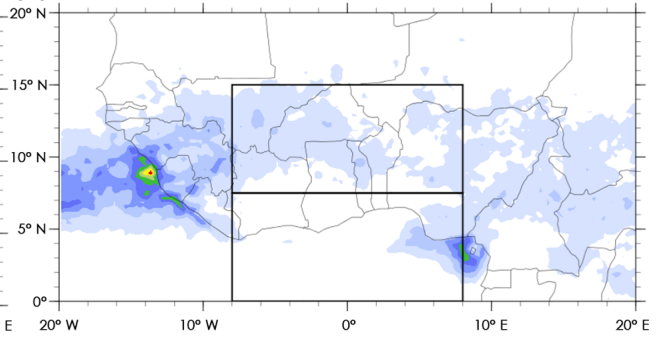

(d) Phase 4
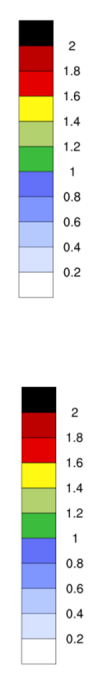

Figure 6. Horizontal distribution of mean precipitation during the four phases of the DACCIWA campaign. Plots are based on TRMM precipitation and given in millimetres per hour. (a) Phase 1 (1-21 June 2016), (b) Phase 2 (22 June-20 July 2016), (c) Phase 3 (21-26 July 2016) and (d) Phase 4 (27-31 July 2016). The black boxes mark the areas used to compute the north-south precipitation difference shown in Fig. 5a. Corresponding anomalies are shown in Fig. S1.

ing to note that despite a strong SHL and an established ACT, rainfall remains strongest along the coast, indicating that monsoon onset has not yet occurred. This aspect will be discussed further in Sect. 4.3. In Fig. 5, significant synoptic disturbances are labelled with the capital letters A-J. These were subjectively identified from $850 \mathrm{hPa}$ streamline plots at 00:00 UTC each day and often show a noticeable correspondence to the precipitation and TCWV behaviour. A summary of their most important characteristics is given in Table 1 and individual tracks are shown in Figs. 11, 13, 14 and 16. The 


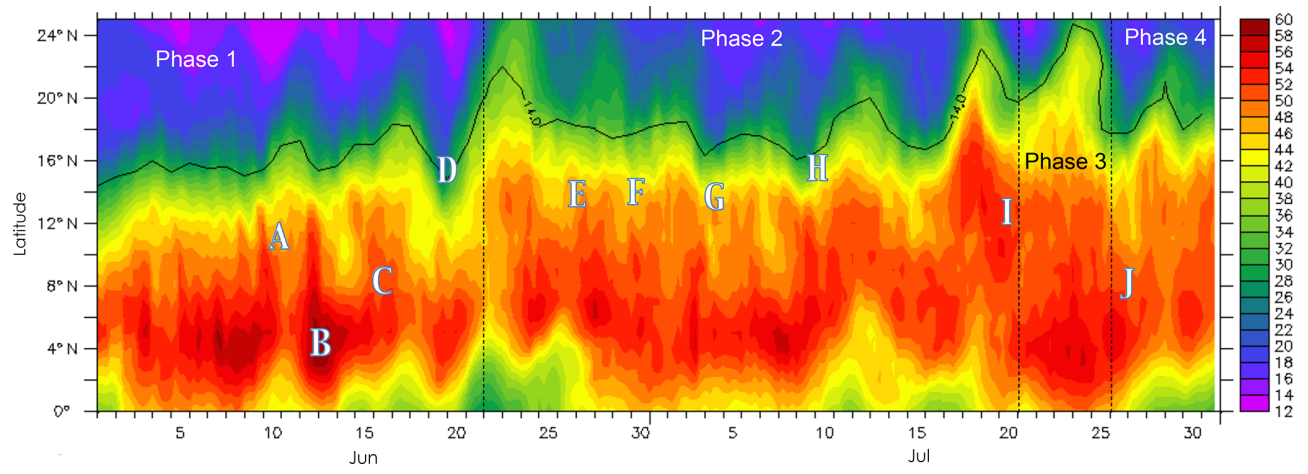

Figure 7. Evolution of TCWV (shading in millimetres) and the ITD (black line, identified from the $14^{\circ} \mathrm{C}$ isoline of $2 \mathrm{~m}$ dew point) during June-July 2016 based on ECMWF operational analysis. The four phases of the DACCIWA campaign and significant synoptic-scale features A-J are marked at the approximate time and latitude of crossing the DACCIWA focus region as in Fig. $5 \mathrm{~b}$.

locations of the feature labels in Figs. 5 and 7 correspond to the times when they cross the Greenwich meridian (i.e. centre of the DACCIWA focus region) and their latitudinal position (Figs. $5 \mathrm{~b}$ and 7 only).

Phase 2 lasts from 22 June to 20 July 2016 and is characterised by a rainfall maximum inland with smaller and less regular fluctuations of the NSPD (Fig. 5a) and only occasional and weaker convective systems around $4^{\circ} \mathrm{N}$ (Fig. 5b). This indicates a fully developed WAM with a deeper penetration of rainfalls and TCWV into the continent, and a northward-shifted ITD, while marine precipitation is restricted to the Bight of Bonny and the waters along the West African west coast (Figs. 6b and 7). Large parts of the inland DACCIWA region were virtually dry during this period, much drier than in other years (Fig. S1b), despite relatively high TCWV values (Fig. 7). The transition from Phase 1 to Phase 2 is marked by strikingly dry conditions across most of the area of interest (Fig. 5b), much reduced TCWV (Fig. 7), strong fluctuations of the ITD (Fig. 7) and an abrupt breakdown of the SHL (Fig. 4a). During Phase 2 the SHL then gradually intensifies and shifts westward (Fig. 4). There is also a gradual increase in coastal upwelling during this period (Fig. 3), which is consistent with more stable, nearsurface monsoonal winds. The behaviour of the ACT, which is relatively weak and shifted to the south during most of Phase 2, does not seem to be closely related to the precipitation shift.

During 21-26 July 2016 (Phase 3), the rainfall maximum shifts back to the coastal zone (Fig. 5a), accompanied by wet conditions spanning large parts of the latitude band from 1 to $22^{\circ} \mathrm{N}$ (Fig. 5b), where TCWV is enhanced and the ITD reaches its northernmost extension (Fig. 7). A horizontal distribution of rainfall during this period (Fig. 6c) shows unusually intense convection across the entire Gulf of Guinea, widespread rain across the entire Sudanian zone and more patchy local maxima stretching into the Sahel and even southern Sahara (see anomalies in Fig. S1c). Even larger amounts are found along the coast of Guinea and Sierra

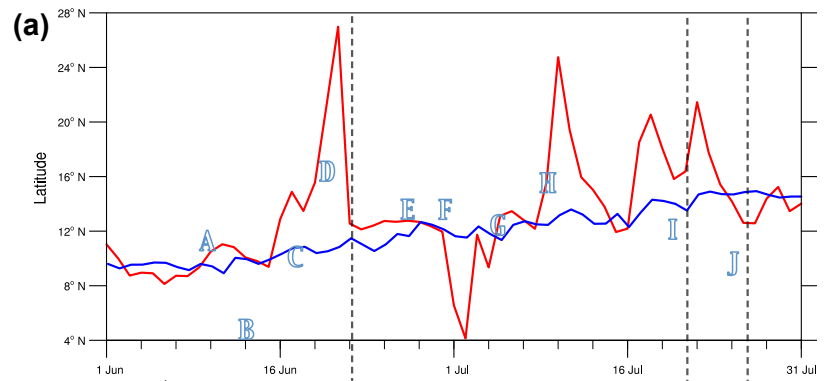

(b)

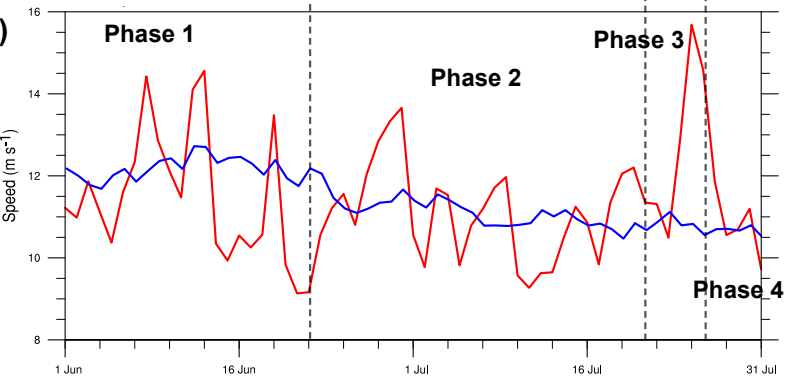

Figure 8. AEJ evolution during June-July 2016. Time series of (a) latitudinal position and (b) mean speed in metres per second of the AEJ objectively identified from ERA-I reanalysis data. The red lines indicate the 2016 evolution, the blue lines the 1987-2016 climatological mean (see Sect. 2.2 for more details). The four phases of the DACCIWA campaign are indicated by vertical lines. The significant synoptic-scale features A-J are marked at the approximate time and latitude of crossing the DACCIWA focus region.

Leone. This wet phase is preceded and accompanied by a second breakdown of the SHL as well as a marked westward shift in its centre (Fig. 4). Coastal upwelling is increased during this period, while no major change in the ACT is seen (Fig. 3).

During the last 5 days of July 2016 (Phase 4), the WAM system returns to a more typical behaviour for this time of the year with a precipitation maximum in the Sahel, similar to Phase 2 (Fig. 5). As in Phase 2, the southern parts of the DACCIWA region are rather dry and coastal rainfalls are re- 
Table 1. Characterisation of the labelled (Column 1) synoptic-scale features. Columns 2 and 3 give the time period and longitude range for which a coherent vortex was tracked in $850 \mathrm{hPa}$ streamlines (see Figs. 11, 13, 14 and 16). Column 4 gives a general description, including aspects such as propagation speed, latitude and reflection in wind and vorticity anomalies.

\begin{tabular}{|c|c|c|c|}
\hline Label & Time & Long & Description \\
\hline A & 9-12 June & $22^{\circ} \mathrm{E}-25^{\circ} \mathrm{W}$ & $\begin{array}{l}\text { fast-propagating }\left(16.8 \mathrm{~m} \mathrm{~s}^{-1}\right) \text { Sudanian }\left(\sim 11^{\circ} \mathrm{N}\right) \text { cyclonic vortex and tropical disturbance, } \\
\text { weak vorticity signal but clear southerly wind signal, long-lived MCSs embedded }\end{array}$ \\
\hline $\mathrm{B}$ & 12-15 June & $9^{\circ} \mathrm{E}-21^{\circ} \mathrm{W}$ & $\begin{array}{l}\text { moderately fast }\left(11.2 \mathrm{~m} \mathrm{~s}^{-1}\right) \text { coastal }\left(\sim 5^{\circ} \mathrm{N}\right) \text { cyclonic vortex and tropical disturbance, } \\
\text { moderate vorticity and meridional wind signals, intense, long-lived MCSs embedded }\end{array}$ \\
\hline $\mathrm{C}$ & 15-18 June & $11^{\circ} \mathrm{E}-8^{\circ} \mathrm{W}$ & $\begin{array}{l}\text { moderately fast }\left(11.0 \mathrm{~m} \mathrm{~s}^{-1}\right) \text { Sudanian }\left(\sim 9^{\circ} \mathrm{N}\right) \text { cyclonic vortex and tropical disturbance, } \\
\text { patchy vorticity and meridional wind signals, long-lived MCS embedded }\end{array}$ \\
\hline $\mathrm{D}$ & 15-25 June & $17^{\circ} \mathrm{E}-23^{\circ} \mathrm{W}$ & $\begin{array}{l}\text { low-pressure trough turning into westward-propagating disturbance with two cyclonic } \\
\text { centres, large meridional wind anomalies, relative dryness, triggering monsoon onset }\end{array}$ \\
\hline $\mathrm{E}$ & 27-30 June & $2^{\circ} \mathrm{E}-27^{\circ} \mathrm{W}$ & $\begin{array}{l}\text { AEW with two cyclonic centres and typical propagation speed of } 9.6 \mathrm{~m} \mathrm{~s}^{-1} \text {, with coherent } \\
\text { signals in meridional wind and vorticity, leading to increased Sahelian rainfall }\end{array}$ \\
\hline $\mathrm{F}$ & 29 June-3 July & $14^{\circ} \mathrm{E}-21^{\circ} \mathrm{W}$ & $\begin{array}{l}\text { AEW with two cyclonic centres and a fast propagation speed of } 10.6 \mathrm{~m} \mathrm{~s}^{-1} \text {, with coherent } \\
\text { signals in meridional wind and vorticity, leading to increased Sahelian rainfall }\end{array}$ \\
\hline $\mathrm{G}$ & 3-8 July & $12^{\circ} \mathrm{E}-18^{\circ} \mathrm{W}$ & $\begin{array}{l}\text { unorganised AEW with ill-defined southern centre, northward moving northern centre } \\
\text { and varying propagation speed, but discernable rainfall signal }\end{array}$ \\
\hline $\mathrm{H}$ & 9-16 July & $12^{\circ} \mathrm{E}-22^{\circ} \mathrm{W}$ & $\begin{array}{l}\text { slowly moving }\left(7.1 \mathrm{~m} \mathrm{~s}^{-1}\right) \text { northern }\left(\sim 15^{\circ} \mathrm{N}\right) \text { cyclonic and southern anticyclonic } \\
\left(\sim 4^{\circ} \mathrm{N}\right) \text { vortex originating from } \mathrm{SH} \text {, westerly wind anomaly between centres }\end{array}$ \\
\hline I & 17-27 July & $23^{\circ} \mathrm{E}-25^{\circ} \mathrm{W}$ & $\begin{array}{l}\text { relatively slow-moving northern }\left(\sim 13^{\circ} \mathrm{N}\right) \text { cyclonic and southern }\left(\sim 5^{\circ} \mathrm{N}\right) \text { anticyclonic } \\
\text { vortex with westerly wind anomaly in-between, creating conditions for wet period }\end{array}$ \\
\hline $\mathrm{J}$ & 23-30 July & $19^{\circ} \mathrm{E}-25^{\circ} \mathrm{W}$ & $\begin{array}{l}\text { mostly slow moving Sudanian }\left(\sim 9^{\circ} \mathrm{N}\right) \text { cyclonic vortex, coherent vorticity but less clear } \\
\text { wind signal, occurring in an environment of MCSs, high moisture and widespread rain }\end{array}$ \\
\hline
\end{tabular}

stricted to the Niger Delta region (Fig. 6d). Rainfall along the coast of Guinea, however, is even more abnormal than in Phase 3 (Fig. S1d). Overall, conditions are somewhat wetter than during Phase 2. This is accompanied by a partial recovery of the SHL (Fig. 4) and weakening of coastal upwelling (Fig. 3).

In the remainder of this section, the four phases outlined above as well as the transition between Phases 1 and 2 (the monsoon onset) will be analysed in detail, focusing on the synoptic-scale features labelled in Fig. 5. To aid the characterisation of these features, the following additional diagrams will be considered (see Sect. 2.2 for more details): (a) objective analyses of AEJ position and speed (Fig. 8), (b) Hovmöller plots of $850 \mathrm{hPa}$ vorticity and meridional wind for the $4-18^{\circ} \mathrm{N}$ latitude band (Fig. 9), and (c) Hovmöller plots of equatorial wave disturbances in the $0-15^{\circ} \mathrm{N}$ band based on TRMM rainfall as well as tracks of long-lived MCSs (Fig. 10).

\subsection{Phase 1: pre-onset (1-21 June 2016)}

As stated in Sect. 4.1, the pre-onset period is characterised by a coastal rainfall maximum (Fig. 5), a strong eastwardshifted SHL (Fig. 4) and a weak ACT (Fig. 3). The AEJ is still located close to the coast during most of this phase
(Fig. 8a; see also Fig. S2a). The first week (1-6 June) is relatively quiet with overall little rainfall across the region (Fig. 5b). The AEJ is anomalously far south (Fig. 8a) with a below-normal intensity (Fig. 8b). No significant coherent features are detected during this period, neither in $850 \mathrm{hPa}$ vorticity and meridional winds (Fig. 9) nor in terms of filtered equatorial waves (Fig. 10). The enhanced vorticity feature starting on 5 June 2016 (Fig. 9) is related to a northern area of high horizontal wind shear (not shown) and is thus not associated with coherent meridional wind signals. The activity of long-lived MCSs is also relatively weak (black lines in Fig. 10; see also Fig. S3).

Between 7 and 15 June 2016 the AEJ begins shifting northward, showing two distinct mean speed maxima of more than $14 \mathrm{~ms}^{-1}$ (Fig. 8). On 7 June the jet maximum is located over southern Chad (not shown). The enhanced shear associated with this feature appears to have supported the formation of a large and long-lived MCS (Fig. 10) that brings substantial rainfall to southern areas (Fig. 5b) and thus creates a minimum in NSPD (Fig. 5a). In the following days, three relatively weak cyclonic disturbances cross the region (Fig. 11). As already mentioned, Table 1 provides a summary of the main characteristics of these disturbances and all subsequent ones. The first disturbance (labelled A 


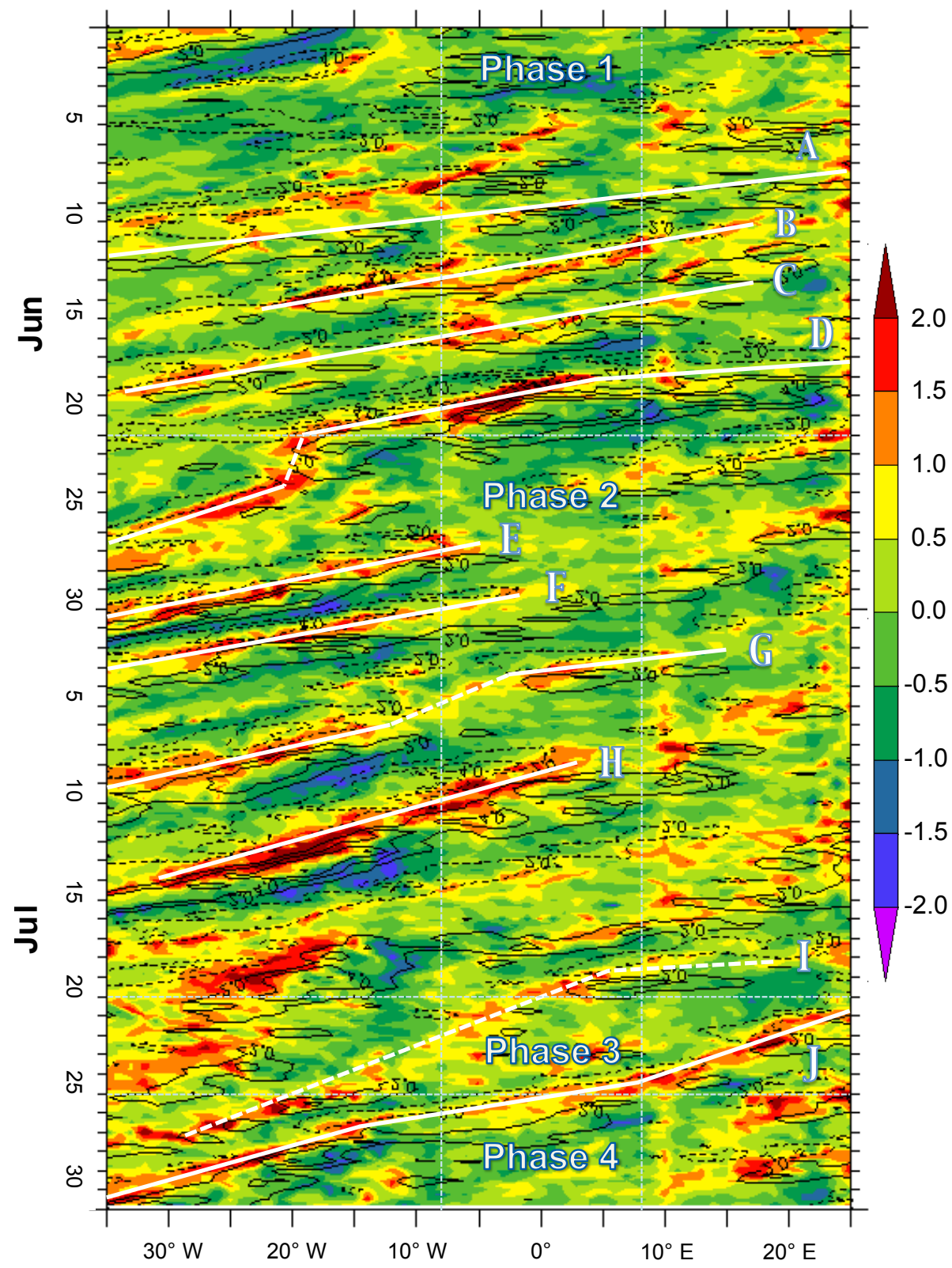

Figure 9. Coherent wind and vorticity features affecting the DACCIWA region. Hovmöller diagram showing $4-18^{\circ} \mathrm{N}$ meridionally averaged vorticity (colours, $10^{-5} \mathrm{~s}^{-1}$ ) and meridional wind (black lines, $\mathrm{ms}^{-1}$ ) based on operational ECMWF analyses at $1^{\circ}$ resolution (in order to smooth noisy vorticity fields). The four phases of the DACCIWA campaign and significant synoptic-scale features A-J are marked as well as the longitudinal bounds of the DACCIWA focus region $8^{\circ} \mathrm{W}-8^{\circ} \mathrm{E}$ (see Fig. 1).

in Fig. 11) propagates quickly westward from eastern Chad to northern Côte d'Ivoire between 9 and 11 June 2016, in accordance with the relatively strong AEJ during this period (Fig. 8b). When it passes the DACCIWA region, the increase in southerly flow seen in Fig. 9 (solid black lines) is associated with an increase in rainfall inland, while coastal rainfall is also still active, leading to an NSPD near zero (Fig. 5a). The vorticity signature of Feature A is relatively weak (Fig. 9), but there are several long-lived MCSs embed- ded in this system and the latter stages are identified as a TD (Fig. 10).

The immediately following second disturbance (labelled B in Fig. 11) propagates a little slower and on a more southern track from the border of Nigeria and Cameroon parallel to the coast out to the Atlantic past $20^{\circ} \mathrm{W}$. When the centre of the vortex passes the DACCIWA region on 12 and 13 June, a strong increase in rainfall over the ocean is observed, creating a sharp minimum in NSPD (Fig. 5a). The slower propagation of this feature is consistent with the larger distance to the 


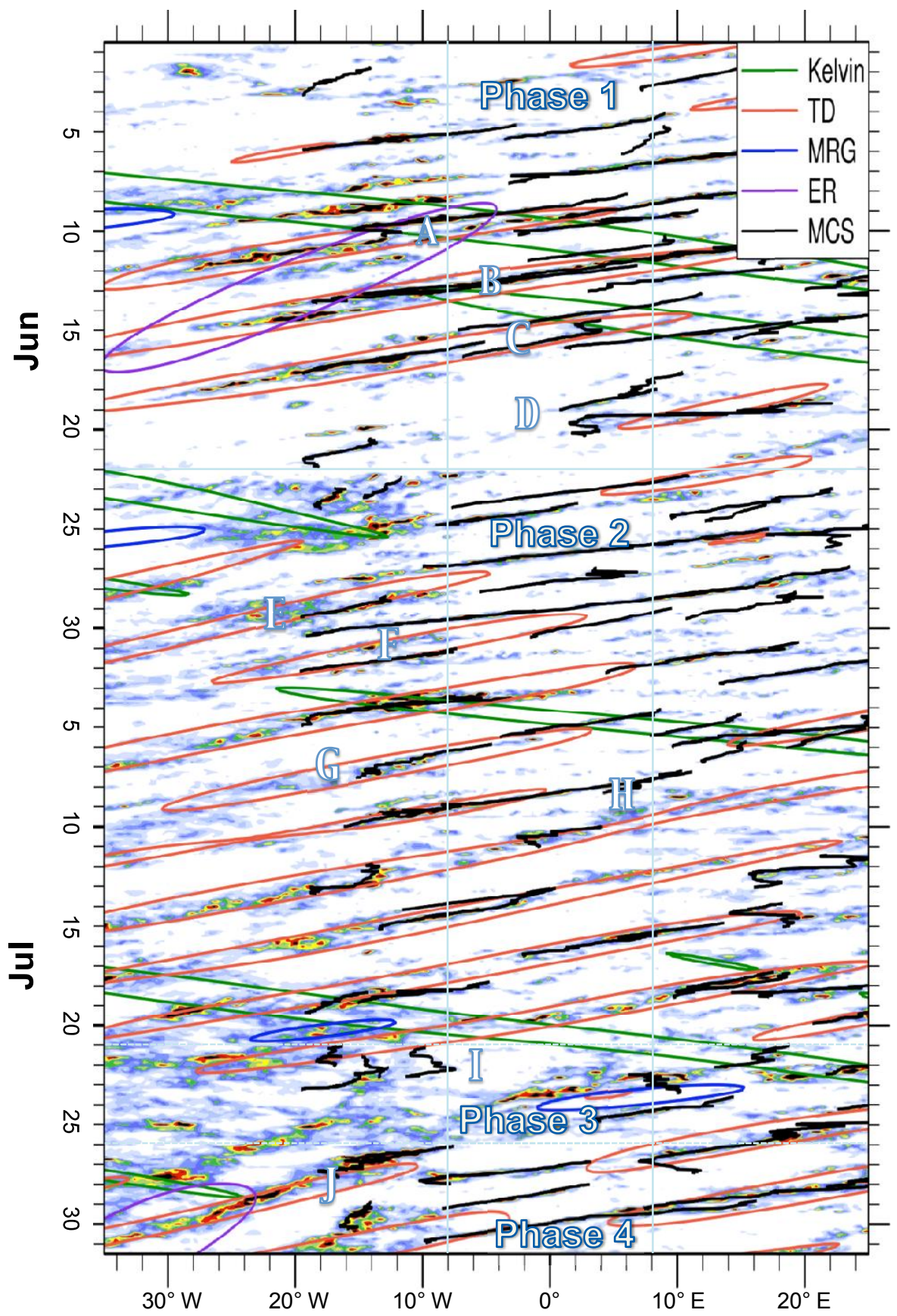

Figure 10. Tropical wave phenomena and long-lived MCSs during June-July 2016. Hovmöller diagram of 5-15 $5^{\circ}$ meridionally averaged precipitation from TRMM ( $\mathrm{mmh}^{-1}$, colour shading according to legend) with objectively identified waves marked with coloured lines according to the legend in the top right corner and long-lived MCSs with at least $24 \mathrm{~h}$ of lifetime marked with thick black lines (for details on detection of both features, see Sect. 2.2). Contour lines for the wave features correspond to a modulation of precipitation of more than $0.12 \mathrm{~mm} \mathrm{~h}^{-1}$. Note that while the tropical waves are identified for the entire longitudinal range of $35^{\circ} \mathrm{W}-25^{\circ} \mathrm{E}$, the $\mathrm{MCS}$ identification is limited to the land-dominated area $20^{\circ} \mathrm{W}-25^{\circ} \mathrm{E}$. The four phases of the DACCIWA campaign and significant synoptic-scale features A-J as well as the longitudinal bounds of the DACCIWA focus region $8^{\circ} \mathrm{W}-8^{\circ} \mathrm{E}$ (see Fig. 1) are marked.

strong AEJ core near $9^{\circ} \mathrm{N}$ (Fig. 8). Feature B shows a more coherent signature in vorticity and meridional wind (Fig. 9), as well as TCWV (Fig. 7), and is identified as a TD with two very long-lived and intense MCSs embedded over the DACCIWA region (Fig. 10).

From 15 to 18 June 2016 the AEJ is weak and shifts northward (Fig. 8), while a third cyclonic feature becomes ev- 


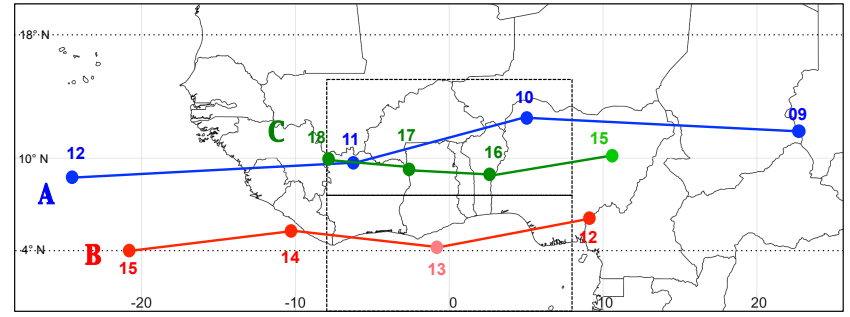

Figure 11. Significant synoptic-scale features during 9-18 June 2016 (Phase 1). To create this graph, vortices were subjectively identified in $850 \mathrm{hPa}$ streamlines based on operational ECMWF analyses. All vortex positions refer to 00:00 UTC with the dates given as numbers. Round symbols mark cyclonic systems (labelled A, B and C). Paler colours are used for days when the vortices were not clearly identifiable. The boxes mark the areas used to compute the NSPD shown in Fig. 5a. The stippled lines show the latitude range used to produce Fig. 9.

ident in the $850 \mathrm{hPa}$ streamlines (labelled $\mathrm{C}$ in Fig. 11). It propagates relatively slowly from eastern Nigeria across the DACCIWA region, reaching northwestern Côte d'Ivoire by 00:00 UTC on 18 June. It is associated with a moderate increase in rainfall inland, while the coast is conspicuously dry, leading to a slightly positive NSPD (Fig. 5a). Interestingly, Feature $\mathrm{C}$ appears to be related to a longer-lived, somewhat patchy vorticity and meridional wind feature (white line in Fig. 9), which is also identified as a TD (Fig. 10). The vortex identified from the streamlines appears to move somewhat slower than this disturbance and is only found during the period of strongest southerlies immediately over the DACCIWA region (not shown). The vorticity feature moves at a similar speed as the embedded MCS (Fig. 10). Interestingly, during the middle part of Phase 1, the rainfall in the 5$15^{\circ} \mathrm{N}$ latitude band appears to be modulated by two Kelvin waves propagating across the DACCIWA region (green lines in Fig. 10), which superpose with the TD signals. There is also some indication for equatorial Rossby wave activity in the western part of the domain, but this signal is harder to see in the unfiltered TRMM data (Fig. 10).

\subsection{Transition from Phase 1 to Phase 2: the onset (16-26 June 2016)}

The monsoon onset is often defined as a more permanent shift in the rainfall maximum into the continent (e.g. Fitzpatrick et al., 2015). According to the NSPD (Fig. 5a), this occurred on 21-22 June in 2016, the transition from Phase 1 to Phase 2. As this date is of such a large importance for the WAM, a dedicated discussion of the 5 days before and after this date is presented here. Overall this 10-day period has relatively low rainfall in the DACCIWA region, the two noteworthy exceptions being the enhanced coastal rainfall around 19 and 20 June and a Sahelian maximum on 24-25 June

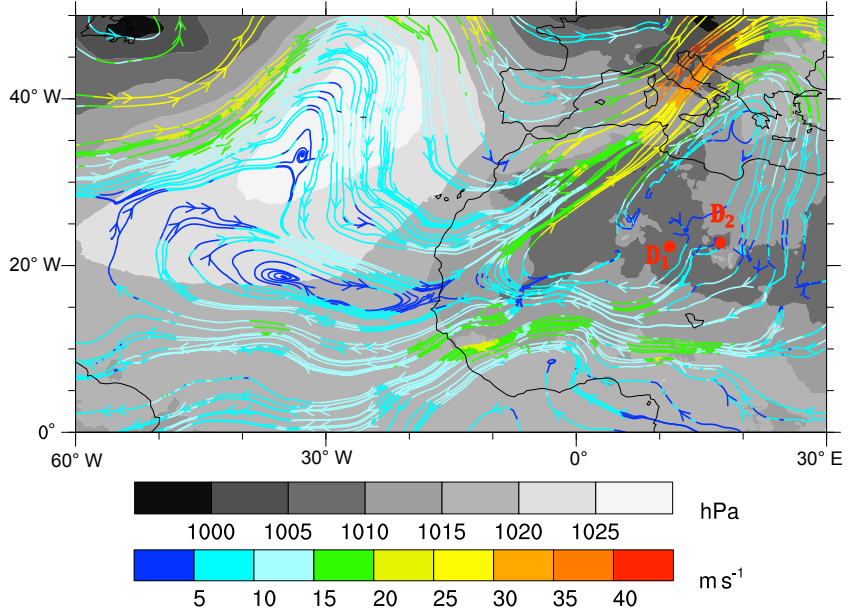

Figure 12. Extratropical influences during the monsoon onset. Shown are streamlines coloured by wind speed (scale at bottom), at $600 \mathrm{hPa}$ and mean sea level pressure (grey shading) at 00:00 UTC on 17 July based on ECMWF operational analyses. The two disturbances from Fig. 13 are marked in red.

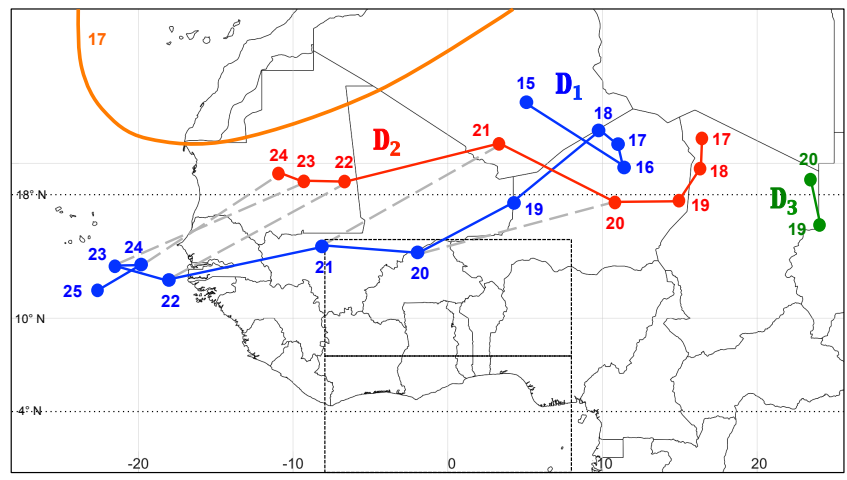

Figure 13. Significant synoptic-scale features during 15-25 July 2016 (transition from Phase 1 to Phase 2). To create this graph, vortices were subjectively identified in $850 \mathrm{hPa}$ streamlines based on operational ECMWF analyses. All vortex positions refer to 00:00 UTC with the dates given as numbers. Round symbols mark cyclonic vortices (labelled $\mathrm{D}_{1}, \mathrm{D}_{2}$ and $\mathrm{D}_{3}$ ) and the thick orange line shows the southernmost extension of a significant trough at $600 \mathrm{hPa}$ (see Fig. 12). Vortices with a joint propagation are linked with dashed grey lines. The boxes mark the areas used to compute the NSPD shown in Fig. 5a. The stippled lines show the latitude range used to produce Fig. 9.

(Fig. 5b). Consistently, the activity of equatorial waves and long-lived MCSs is strongly suppressed (Fig. 10).

The synoptic development during the onset is characterised by substantial extratropical influences disturbing the circulation over northern Africa with high-amplitude waves and wave breaking in the subtropical upper troposphere. On 15 June 2016, the polar and subtropical jets merge over the Mediterranean Sea and a high-amplitude ridge is located upstream over the central North Atlantic (not shown). This pe- 
riod is characterised by a substantial drop in the inertial stability index defined by Cook (2015) but negative values are only reached for short periods (not shown). While the Atlantic ridge continues to propagate eastward, the downstream trough and ridge amplify strongly until 17 June. On this day, the trough stretches all the way to the Mauritanian coast and leads to a strong southwesterly flow at $600 \mathrm{hPa}$ across the western Sahara (Fig. 12). It is conceivable that subsidence associated with the ridge stretching from eastern Europe into northeastern Africa (Fig. 12) contributed to the suppression of rainfall evident from Fig. 5b. The inflow of cool maritime air from the Atlantic Ocean leads to an abrupt ventilation of the SHL, causing a weakening of its intensity and rapid eastward shift in the centre (Fig. 4) with some resemblance to the situation Todd et al. (2013) refer to as the "maritime phase". According to http://misva.sedoo.fr, the intra-seasonal SHL index reached a distinct maximum on 17 and 18 June 2016. The extreme nature of this cold surge is visible in $20^{\circ} \mathrm{W}-0^{\circ} \mathrm{E}$ averaged temperature anomalies at $850 \mathrm{hPa}$, showing a very distinct and unusual cooling during this period, with anomalies below $-6 \mathrm{~K}$ north of $30^{\circ} \mathrm{N}$ and below $-4 \mathrm{~K}$ down to almost $20^{\circ} \mathrm{N}$ (Fig. S4a). Over the next few days, the whole wave slowly drifts eastwards, allowing the northerlies associated with the trough to penetrate into the eastern parts of the Sahara as well. The associated cooling, which is overall less dramatic in the east (Fig. S4b), finally leads to the conspicuous collapse of the SHL between 20 and 25 June 2016 shown in Fig. 4a. This development is also reflected in an abrupt northward jump of the AEJ core accompanied by a significant weakening around 21 June 2016 (Fig. 8).

Within the large area of reduced surface pressure to the southeast of the trough that stretches unusually far south (Fig. 12), three cyclonic vortices form at $850 \mathrm{hPa}$ (Fig. 13). The first one (labelled $\mathrm{D}_{1}$ ) first appears over the Hoggar Mountains in southern Algeria on 15 June 2016 and then remains rather stationary over northern Niger between 16 and 18 June 2016. The second (labelled $\mathrm{D}_{2}$ ) forms farther to the east and slowly moves along the border between Chad and Niger between 17 and 19 June 2016 (see also Fig. 12). The last one (labelled $\mathrm{D}_{3}$ ) is only discernable in $850 \mathrm{hPa}$ streamlines on 19 and 20 June 2016 along the border of northern Chad and Sudan. On these two days, the three centres form a zonally elongated area of cyclonic rotation with marked northerlies to the west and southerlies to the east. Between 19 and 21 June 2016, $D_{1}$ and $D_{2}$ rotate cyclonically around each other while beginning to propagate westward in a fashion similar to an AEW (Fig. 13). Both cyclonic centres slow down and weaken between 22 and 25 June 2016 near the West African west coast. To the northwest of $D_{1}$ and $D_{2}$, northerly flow reaches values of $15-25 \mathrm{~m} \mathrm{~s}^{-1}$ between 18 and 21 June 2016 (not shown), which leads to a marked southward push of TCWV (Fig. 7).

Figure 9 shows how this unusual development is reflected in $850 \mathrm{hPa}$ vorticity and meridional wind (labelled D). On 18 June $2016, D_{1}$ and $D_{2}$ are still located to the north of $18^{\circ} \mathrm{N}$ and thus signals in the Hovmöller plot are weak. On 19 June 2016, the strong northerlies begin to penetrate into the DACCIWA region, helping to suppress rainfall (see Fig. 5b). This is followed by unusually large vorticity values on 20 June 2016, when $D_{1}$ moves south of $18^{\circ} \mathrm{N}$ (Fig. 13). On 20 and into 21 June 2016 a wide area of very strong southerlies spreads across the DACCIWA region. These bring moisture far into the continent, shifting the ITD northward (Fig. 7), and thus create the conditions for an inland rainfall maximum between 23 and 25 June 2016, indicating that the onset has in fact occurred. After the turbulent transition phase, the WAM system becomes relatively quiet and the AEJ slowly gets re-established near its climatological latitudinal position until 26 June 2016 (Fig. 8) with the SHL also beginning to re-intensify (Fig. 4).

The analysis above strongly suggests that in 2016 the monsoon onset was triggered by very strong interactions with the midlatitudes that supported a suppression of rainfall over West Africa. Low-rainfall conditions around the onset have been documented for other years as well (Sultan and Janicot, 2003).

\subsection{Phase 2: post-onset (22 June-20 July 2016)}

Phase 2 comprises a period of relatively undisturbed monsoon conditions. The entire DACCIWA aircraft campaign fell into this period (see Flamant et al., 2017). The NSPD is positive through most of this phase and is modulated by the significant weather systems E-I, with centres between 12 and $16^{\circ} \mathrm{N}$ and thus farther north than the Phase 1 features A-C (see Fig. 5). This period was anomalously dry along the Guinea Coast (Fig. S1b). Features E-I also modulate the speed and latitude of the AEJ (Fig. 8).

At the very beginning of this phase, between 23 and 26 June 2016, while the monsoon is still being established, a relatively weak (and therefore unlabelled) cyclonic feature crosses the southern part of SWA, creating some moderate rainfalls in the Sahel around 24 June 2016 (Fig. 5b). This is the first time during the DACCIWA campaign that the precipitation maximum has fully shifted inland. After this system, the SHL starts intensifying and shifts northward (Fig. 4a), the AEJ accelerates (Fig. 8b) and a deep southwesterly monsoon flow gets established (not shown).

Between 27 June and 8 July 2016, three AEWs (Fig. 14a) associated with moderate fluctuations in TCWV (Fig. 7) develop. The first two (Features $\mathrm{E}$ and $\mathrm{F}$ ) form on a relatively well organised AEJ (Fig. 8b) and show rather classical propagation characteristics with coherent signals in meridionally averaged vorticity and meridional wind at $850 \mathrm{hPa}$ (Fig. 9). Both have two cyclonic centres at $850 \mathrm{hPa}$ straddling the jet to the north and south (Fig. 14a) and are also objectively identified as TDs (Fig. 10). Feature E, which forms near the Greenwich meridian, appears to be associated with the slight rainfall enhancement on 26 and 27 June 2016, while Feature $\mathrm{F}$ forming near $12^{\circ} \mathrm{E}$ creates a peak in rain in the northern 


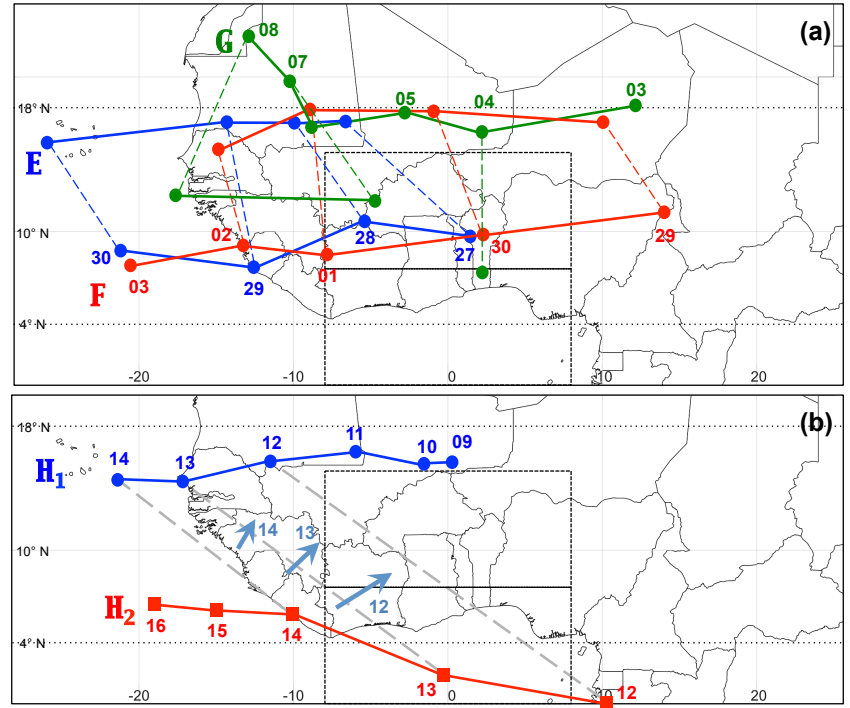

Figure 14. Significant synoptic-scale features during 27 June-16 July 2016 (beginning (a) and middle (b) of Phase 2). To create these graphs, vortices were subjectively identified in $850 \mathrm{hPa}$ streamlines based on operational ECMWF analyses. All vortex positions refer to 00:00 UTC with the dates given as numbers. Round symbols mark cyclonic systems (labelled E, F, G and $\mathrm{H}_{1}$ ), squares anticyclonic systems (labelled $\mathrm{H}_{2}$ ). Vortices with a joint propagation are linked with dashed grey lines. The cores of significant $850 \mathrm{hPa}$ jets are indicated with light blue arrows, again with the date at 00:00 UTC given as numbers. The boxes mark the areas used to compute the NSPD shown in Fig. 5a. The stippled lines show the latitude range used to produce Fig. 9.

box on 29 June 2016 (Fig. 5b). Finally, Feature G forms during a period when the AEJ weakens and becomes more fragmented, which makes its latitudinal position vary strongly (Fig. 8). This leads to less clear and slower propagation behaviour (Fig. 14a). The northern centre propagates from central Niger to eastern Mauritania between 3 and 6 July 2016 and then drifts northwestward towards the border with Western Sahara. This behaviour is accompanied by a rapid shift in the SHL to the west (Fig. 4b). The southern centre shows a less coherent propagation. This is consistent with the relatively patchy signals in wind and vorticity shown in Fig. 9, apart maybe from the final stages over the open Atlantic Ocean. Feature $\mathrm{G}$ is also not matched with a TD like the previous features are (Fig. 10). Nevertheless, a marked increase in rainfall is observed when this feature crosses the DACCIWA region on 4 July 2016 (Fig. 5b).

After that, between 9 and 16 July 2016, a fundamentally different and quite unusual development occurs. While in the north, a cyclonic feature slowly tracks from eastern Mali to Cabo Verde between 8 and 13 July 2016 and then out to the Atlantic (Feature $\mathrm{H}_{1}$ in Fig. 14b), there is no clear corresponding southern vortex. Instead, an anticyclonic system $\left(\mathrm{H}_{2}\right)$ slowly propagates from Gabon on 11 July across the tropical eastern Atlantic, reaching the coast of Sierra Leone

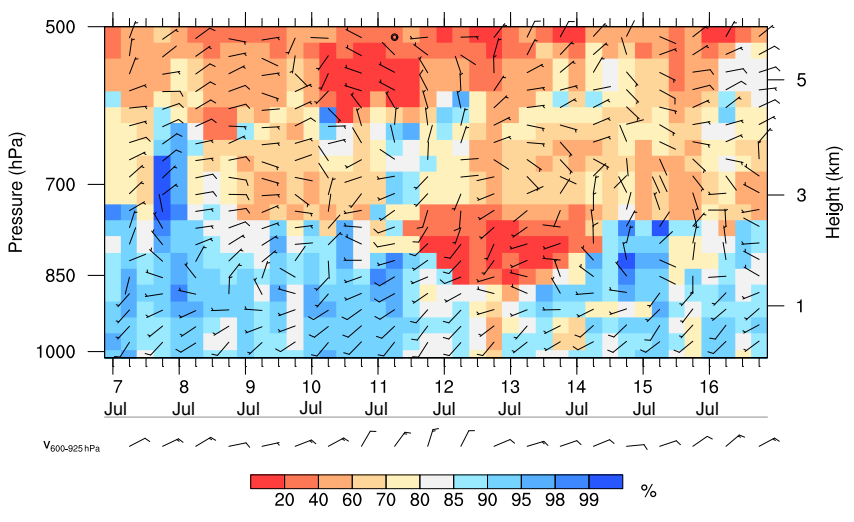

Figure 15. Vertical structure of the atmosphere during part of Phase 2. Shown are relative humidity (shading according to scale, four times daily), wind (barbs) and 600-925 hPa vertical wind shear (below main plot) (both two times daily) from radiosondes launched at Abidjan (for location see Fig. 1) during 7-16 July 2016.

on 14 July 2016, after which it begins to weaken over the ocean to the west. As this system moves a little faster than its cyclonic counterpart to the north, the two centres approach each other, creating an area of marked low- to mid-level southwesterly winds in between them, particularly on 1214 July 2016 along the western border of the DACCIWA region (arrows in Fig. 14b). This behaviour is associated with a weakening and northward shift in the AEJ (Fig. 8). It is conceivable that these westerly wind anomalies also helped to intensify coastal upwelling as shown in Fig. 3. Given the zonal distance between the two centres, both positive and negative vorticity signals are apparent in the Hovmöller plot shown in Fig. 9, although the negative one is only strong past $10^{\circ} \mathrm{W}$. Propagation of these two features is relatively slow, with about $7 \mathrm{~m} \mathrm{~s}^{-1}$. While the signal in the northerlies at $850 \mathrm{hPa}$ is somewhat patchy, the signal in the southerlies, created by the positive superposition of the wind disturbances associated with the staggered northern and southern vortices, is coherent and strong, particularly to the west of $10^{\circ} \mathrm{W}$ (Fig. 9), as also reflected in TCWV (Fig. 7). This has likely supported a deeper inland penetration and slight intensification of rainfall (Fig. 5b). Given the somewhat unusual behaviour of this system, it is no surprise that there is no matching between the TDs and long-lived MCSs objectively identified during this period (Fig. 10). This propagating cyclonic-anticyclonic vortex couplet appears unrelated to any of the classical equatorial waves, but the slow propagation speed and the opposing circulation centres are consistent with the 6-9-day wave regime described by Diedhiou et al. (1999). To the best of our knowledge, the dynamical origin of such features is still somewhat unclear. In particular, the southern origin of the anticyclonic centre and its faster propagation seem unusual.

An interesting effect on the coastal region is that the southern anticyclonic vortex (Feature $\mathrm{H}_{2}$ in Fig. 14b) appears to have brought with it dry air from the area of subsidence in 
the equatorial zone or even SH. To illustrate this, Fig. 15 shows a time series of radiosoundings made four times daily from Abidjan for the period 7-16 July 2016. While most days show a well-developed monsoon layer with high relative humidity and winds from westerly directions, very dry air suddenly intrudes into the $850-700 \mathrm{hPa}$ layer at midday on 11 July (drop from $\sim 85$ to under $20 \%$ ) persisting until the morning of 14 July 2016. Winds blow from southwesterly to westerly directions during this period. Indications of aged aerosol particles were found when the DACCIWA research aircraft penetrated this layer over several days. These aged aerosol particles were likely from fires in the SH (Flamant et al., 2017). Interestingly the usually easterly $600-925 \mathrm{hPa}$ shear vector backs to northerly just before the dry event signalling the changes in the $600 \mathrm{hPa}$ circulation due to the vortex couplet.

\subsection{Phase 3: wet westerly regime (21-26 July 2016)}

Phase 3 is characterized by wet conditions stretching from the tropical Atlantic far into the Sahel and even southern Sahara, particularly on 23-25 July 2016 (Fig. 5). Rainfalls are most abundant over the ocean, particularly off the coast of Nigeria and stretching west to Côte d'Ivoire as well as off the coasts of Liberia and Guinea (Fig. 6), creating large positive anomalies (Fig. S1c). There is also a marked Sahelian band that dips south into Ghana. The relatively large rainfall over the ocean coincides with an area of enhanced meridional SST gradients (Fig. 3) that influence surface wind convergence. Within the DACCIWA region $\left(8^{\circ} \mathrm{W}-8^{\circ} \mathrm{E}\right)$, rainfalls to the south of $7.5^{\circ} \mathrm{N}$ dominate, leading to a sharp drop in NSPD to negative values during this period (Fig. 5a). Similar to the monsoon onset period during the transition from Phase 1 to Phase 2, Phase 3 is characterised by a breakdown of the SHL (Fig. 4a) and low inertial stability according to the index defined by Cook (2015) (not shown), but this time the responsible cold intrusion from the midlatitudes occurs over northeastern Africa (Fig. S4b), leading to a marked westward excursion of the SHL (Fig. 4b). Triggered by an upper-wave in the subtropics, an intensification of the low-level northeasterlies is observed, particularly on 23 and 24 July 2016 over Egypt and Sudan. Such a situation has been referred to as a cold surge by Vizy and Cook (2009), and this type appears to be more frequent than the event in the west before the onset (see Sect. 4.3).

An unusual and interesting synoptic development leads up to this event. On 17 July 2016, an anticyclonic centre appears over the northern Central African Republic and swiftly propagates westward, reaching the border between Nigeria and Benin on 19 July 2016 (propagation speed $\sim 12 \mathrm{~m} \mathrm{~s}^{-1}$; Feature $I_{2}$ in Fig. 16). Strong southerlies ahead of this system lead to an increase in TCWV (Fig. 7). After this day, the vortex slows down substantially (average propagation speed $\sim 4 \mathrm{~m} \mathrm{~s}^{-1}$ ) and shifts to a more southern track just off the Guinea coast and then out to the open Atlantic, reaching

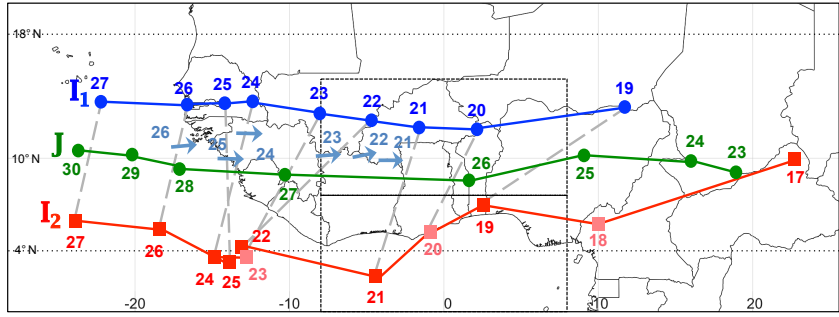

Figure 16. Significant synoptic-scale features during 17-30 July 2016 (end of Phases 2-4). To create this graph, vortices were subjectively identified in $850 \mathrm{hPa}$ streamlines based on operational ECMWF analyses. All vortex positions refer to 00:00 UTC with the date given as numbers. Round symbols mark cyclonic systems (labelled $\mathrm{I}_{1}$ and $\mathrm{J}$ ), squares anticyclonic systems (labelled $\mathrm{I}_{2}$ ). Paler colours are used for days when the vortices were not clearly identifiable. Vortices with a joint propagation are linked with dashed grey lines. The cores of significant $850 \mathrm{hPa}$ jets are indicated with light blue arrows, again with the dates at 00:00 UTC given as numbers. The boxes mark the areas used to compute the NSPD shown in Fig. 5a. The stippled lines show the latitude range used to produce Fig. 9.

$25^{\circ} \mathrm{W}$ on 27 July 2016 . During this period the vortex centre is not always clearly identifiable. Somewhat similar to Feature H (see Fig. 14b), the anticyclonic vortex is accompanied by a cyclonic centre to the north, which is first evident in streamlines at $850 \mathrm{hPa}$ on 19 July 2016 close to the border between northeastern Nigeria and Chad (Feature $\mathrm{I}_{1}$ in Fig. 16). During the slow propagation phase from 21 to 26 July 2016, when the two centres are almost aligned latitudinally with a distance of about $10^{\circ}$, a strong westerly jet develops between them with a maximum near $10^{\circ} \mathrm{N}$, which also propagates westward. The occurrence of this jet (see arrows in Fig. 16), which brings large amounts of moisture into SWA from the west, where much warmer SSTs prevail, exactly marks the beginning and end of Phase 3 . Nicholson (2009) and Nicholson and Webster (2007) have shown that summers with a strong westerly flow at $850 \mathrm{hPa}$ are on average associated with particularly wet conditions. The situation discussed here is therefore one possible synoptic-scale manifestation of this climatological result. Finally, southerlies to the east of $\mathrm{I}_{1}$ lead to a northward extension of the moist zone and an unusual ITD position at $24^{\circ} \mathrm{N}$ (Fig. 7).

As with Feature $\mathrm{H}$, the increasing westerly flow between the cyclonic and anticyclonic centres leads to a weakening and north- and eastward shift in the AEJ (Fig. 8, Fig. S2c) as well as an increase in coastal upwelling (Fig. 3). The weakening of the AEJ may also be related to the weakened SHL discussed above. However, in contrast to Feature H, the latitudinal alignment of the vortices leads to a cancellation of signals in the Hovmöller diagram, making Feature I barely detectable in Fig. 9. So unusual is this situation that there is also very little in terms of objectively identified wave features during this period (Fig. 10). However, some modula- 


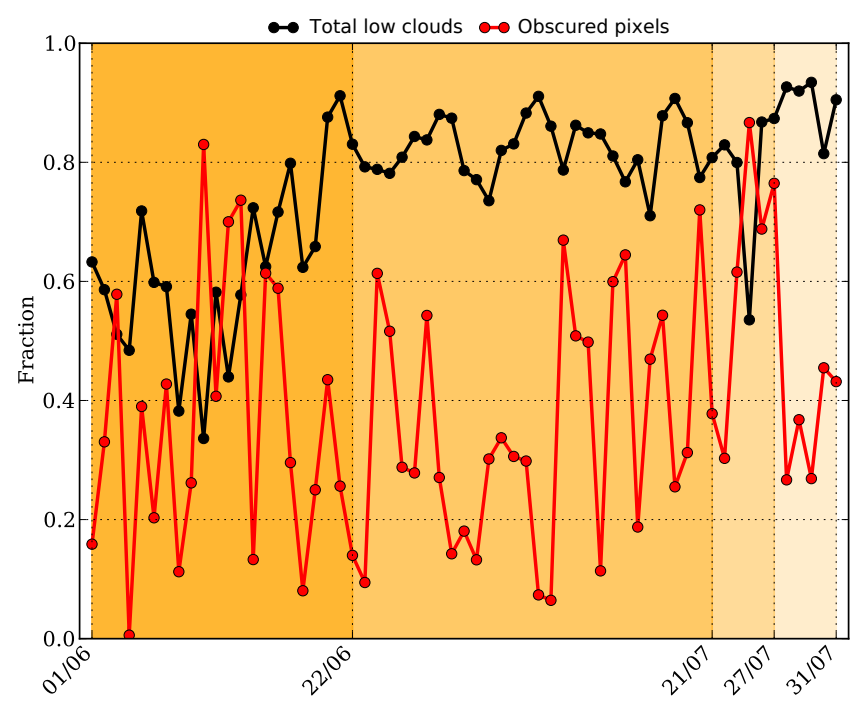

Figure 17. Time evolution of low-cloud fraction over the DACCIWA focus region $\left(5-10^{\circ} \mathrm{N}, 8^{\circ} \mathrm{W}-8^{\circ} \mathrm{E}\right.$, land pixels only; see Fig. 1 for location) during June-July 2016. Depicted as a black line is the average fraction of pixels covered with low clouds (i.e. cloudtop pressure of $800 \mathrm{hPa}$ or higher). Pixels that are covered with obscuring mid- or high-level clouds (fraction given as red line) are disregarded, leading to a relatively large uncertainty in the low-cloud estimates on some days. Basis for this analysis is daily 00:00 UTC CLAAS-2 images (see Sect. 2.1). The four phases of the DACCIWA campaign are marked with different orange shadings.

tion of rainfall by an eastward-propagating Kelvin wave is evident between 18 and 22 July 2016. Mounier et al. (2008) also discuss enhanced westerly inflow, moist conditions and a Kelvin wave influence in connection with the QBZD but the match with their concept is hard to establish for a single case. Feature I is too slow to match the 6-9-day wave regime described by Diedhiou et al. (1999).

\subsection{Phase 4: recovery (27-31 July 2016)}

On 26 July 2006 the widespread rainfall characterising Phase 3 ceases and the precipitation maximum shifts back to the Sahel for the rest of the DACCIWA campaign period, as indicated by a positive NSPD (Figs. 5 and $6 \mathrm{~d}$ ). There is also evidence for a return of the SHL and the ITD to more climatological positions and intensity (Figs. 4 and 7). Thus, overall this phase marks the return to more undisturbed monsoonal conditions similar to Phase 2. A last significant cyclonic feature occurs during this period (Fig. 16, labelled J). This feature is first detected over South Sudan on 23 and 24 July 2016. Until 27 July it swiftly crosses the DACCIWA region, reaching the Guinea highlands. After that, it slows down over the Atlantic on 28-30 July 2016. Figure 8 shows that the period of fast propagation is concomitant with an enhanced and southward-shifted AEJ. Feature J can be identified well in the north-south averaged $850 \mathrm{hPa}$ vorticity in the eastern and western parts of the study region but is somewhat diffuse around $10^{\circ} \mathrm{W}$ (Fig. 9). Nevertheless, the fast-propagation phase is evident from the vorticity as well. Meridional wind signals associated with Feature J, however, are rather weak and only the western parts are concomitant with an objectively identified TD, which in turn appears to be related to a long-lived MCS (Fig. 10). Feature J also creates some mild fluctuations in TCWV (Fig. 7).

\section{Impact on low clouds, dust, biomass burning aerosol and city pollution dispersion}

After the detailed discussion of the large-scale settings in Sect. 3 and the synoptic evolution in Sect. 4, this section aims to discuss the impact of these variability patterns on low clouds and atmospheric composition, two particular scientific interests of the DACCIWA project (Knippertz et al., 2015a). Evaluating the behaviour of low clouds is difficult over SWA in summer due to a relatively sparse observational network at the surface and regular obscuring by mid- and high-level clouds (van der Linden et al., 2015). Figure 17 shows the fraction of low clouds (defined here as cloud-top pressure of $800 \mathrm{hPa}$ and lower) daily at 00:00 UTC in the $5-10^{\circ} \mathrm{N}, 8^{\circ} \mathrm{W}-8^{\circ} \mathrm{E}$ box (see Fig. 1) as analysed from the CLAAS-2 dataset (see Sect. 2). This fraction is relative to the number of pixels not obscured by higher clouds, which can be as high as $85 \%$ (red curve in Fig. 17), indicating a large uncertainty in the low-cloud estimate. Despite this, a clear difference in low-cloud cover between the four phases can be seen. Typical fractions during Phase 1 range around $60 \%$. Given the large uncertainty, day-to-day variations should be regarded with caution. Thus, it is no surprise that the impact of individual synoptic features is generally hard to discern. Only the wet Feature A and dry Feature D stand out, with a high fraction of obscuring high clouds and a low fraction of low clouds for Feature A and the opposite for Feature D. During Phase 2, fractions of low clouds typically range around $85 \%$, while the very variable fraction of obscuring high clouds is on average a little lower than in Phase 1 (Fig. 17). This suggests that the onset is a prerequisite for the occurrence of the extensive stratus decks in SWA. Again, a clear influence of the synoptic features E-I is hard to discern. During Phase 3, the wet 24 July 2016 stands out as a day with a very high fraction of obscuring clouds and a very low (but also very uncertain) fraction of low clouds. Finally, Phase 4 returns to the more typical abundant low and less-frequent high clouds, also observed during Phase 2. During Phase 1, there is frequent evidence for a land-sea breeze convergence, creating clouds in a line parallel to the coast around midday, at least in areas away from deep convection (not shown). Such behaviour is much more difficult to detect during the cloudier Phases 2-4.

Figure 18 shows vertically integrated fields from the ECMWF CAMS-IFS analysis, again averaged zonally from 
$8^{\circ} \mathrm{W}$ to $8^{\circ} \mathrm{E}$. The loading of mineral dust is given as DAOD at $550 \mathrm{~nm}$ (Fig. 18a), while the impact of biomass burning is indicated here through the vertically integrated number of $\mathrm{CO}$ molecules per surface area (Fig. 18b). With respect to dust, differences between the four phases are again evident. Before the onset, the dust plume stretches farther south and sometimes even reaches the coast (around $6^{\circ} \mathrm{N}$ ). In particular, Features $\mathrm{C}$ and D create significant southward excursions of the dust plume, in contrast to the relatively weak southern disturbance B and the fast-propagating disturbance A. With the onset in Phase 2, the dusty zone retreats to the north of $8^{\circ} \mathrm{N}$ with visible modulation by all four cyclonic features E, F, G and $\mathrm{H}$. The area of southwesterlies between the cyclonic vortex $\mathrm{H}_{1}$ and the anticyclonic vortex $\mathrm{H}_{2}$ (see Fig. 14b) pushes the dust northwards. A few days later, a similar but even stronger northward push to beyond $15^{\circ} \mathrm{N}$ is evident in the aftermath of Feature I, creating a relatively dust-free Phase 3. Finally, a return to conditions similar to Phase 2 occurs with the arrival of Feature $\mathbf{J}$ and throughout Phase 4.

For CO (Fig. 18b), the dispersal of the SH biomass burning plume northwards generally covers a wider latitudinal range and the modulation by the four phases and the 10 synoptic features is not quite as clear as for the dust. During Phase 1 a considerable amount of $\mathrm{CO}$ reaches as far north as the Sahel, particularly in the area of southerlies following the passage of the centre of Feature A (see also Fig. 9). The more southern Feature B also instigates a northward transport, but this does not reach $10^{\circ} \mathrm{N}$. Finally, Feature $\mathrm{C}$ is associated with a latitudinally extended but somewhat weaker $\mathrm{CO}$ plume. Comparing the two panels of Fig. 18 shows that during most of Phase 1 dust and biomass burning signatures coexisted in the vertical column over SWA, particularly in the latitudinal range $8-10^{\circ} \mathrm{N}$. The arrival of Feature D associated with the monsoon onset pushes higher $\mathrm{CO}$ values back into the $\mathrm{SH}$, with the exception of a small plume around 20 June 2016. After the onset, higher CO slowly returns to the DACCIWA region, reaching a peak northward extent of $12^{\circ} \mathrm{N}$ around 2 July 2016. For the rest of Phase 2 and until the arrival of Feature I, CO retreats to the coastal and oceanic areas. Remarkably, the time after the passing of Feature H, which is associated with an anticyclonic vortex from the SH, does not show outstanding vertically integrated $\mathrm{CO}$ concentrations. The DACCIWA aircraft frequently measured aged aerosol particles during this period. Further study is needed to check where this aerosol comes from and how deep the layer was vertically using the detailed field measurements. A marked increase in $\mathrm{CO}$ is found to occur with the arrival of Feature I, leading up to the highest values during the entire 2-month period according to CAMS-IFS. It appears that this plume is transported into the region around the anticyclonic feature $I_{2}$ (Fig. 16). Finally, towards Phase 4, Feature $\mathbf{J}$ is associated with a return to values similar to the middle of Phase 2. It is interesting to note that during Phases 2-4, there is generally very little overlap between the vertically

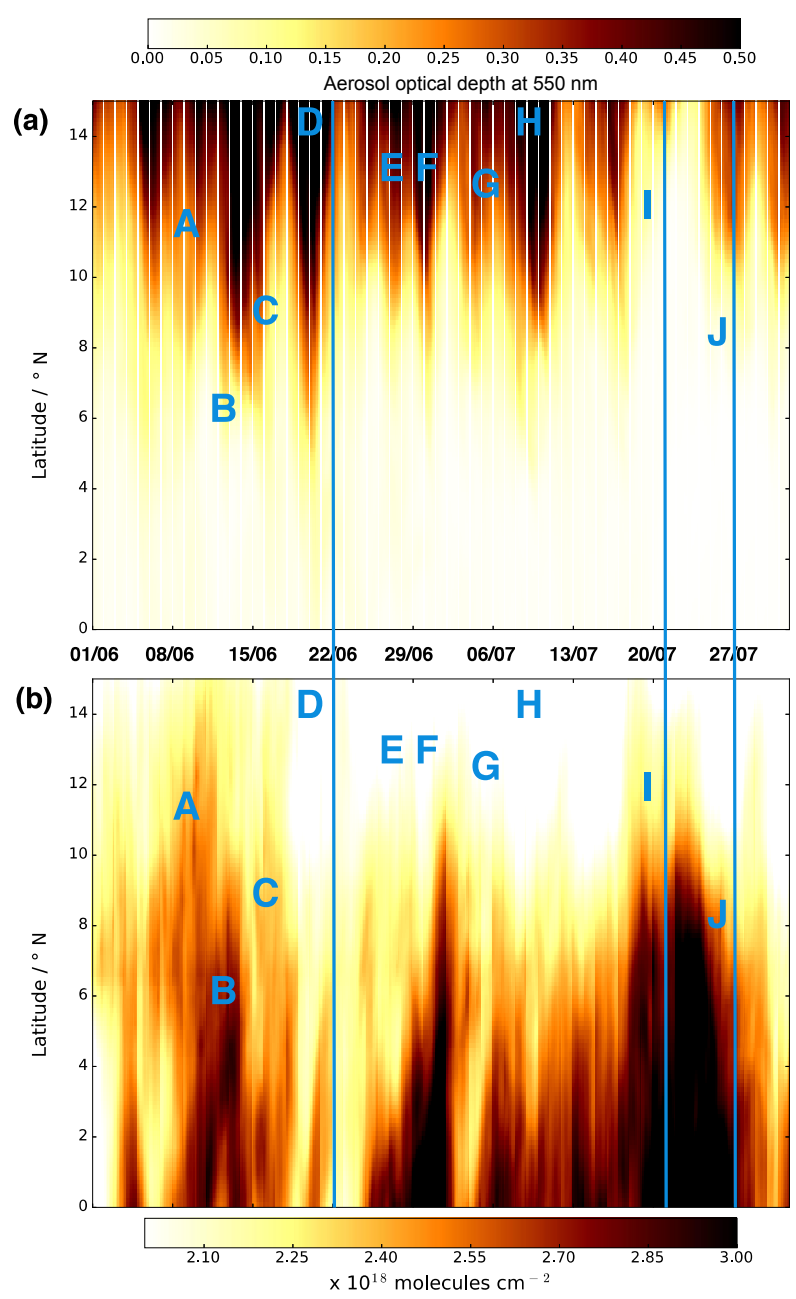

Figure 18. Occurrence of mineral dust (a) and CO (b) plumes over the DACCIWA region. Hovmöller plots for the longitude range $8^{\circ} \mathrm{W}-8^{\circ} \mathrm{E}$ covering the whole June-July 2016 period generated from CAMS-IFS forecast data. Mineral dust plumes are indicated by DAOD at $550 \mathrm{~nm}$ and show the transport of dust from north of the domain (i.e. Sahel and Sahara). The CO is column integrated and primarily shows the transport of air from the SH influenced by biomass burning. The four phases of the DACCIWA campaign are indicated with blue lines. The most significant synoptic features A$\mathrm{J}$ are marked at the approximate time and latitude of crossing the DACCIWA focus region.

integrated dust and CO fields (cf. Fig. 18a with b) in contrast to Phase 1. During most of this time, there appears to be a narrow, meandering, relatively clean strip of air with dust to the north and $\mathrm{CO}$ to the south.

Finally, the dispersion of urban pollution plumes from the five cities of greatest interest to DACCIWA (Abidjan, Kumasi, Accra, Lomé and Cotonou) is discussed based on FLEXPART and HYSPLIT results (see Sect. 2.2). Figure 19 illustrates the spatial distribution of particles emitted and dispersed during Phases 1 and 2 simulated by the FLEXPART model. During Phase 1, when the monsoon flow is less es- 

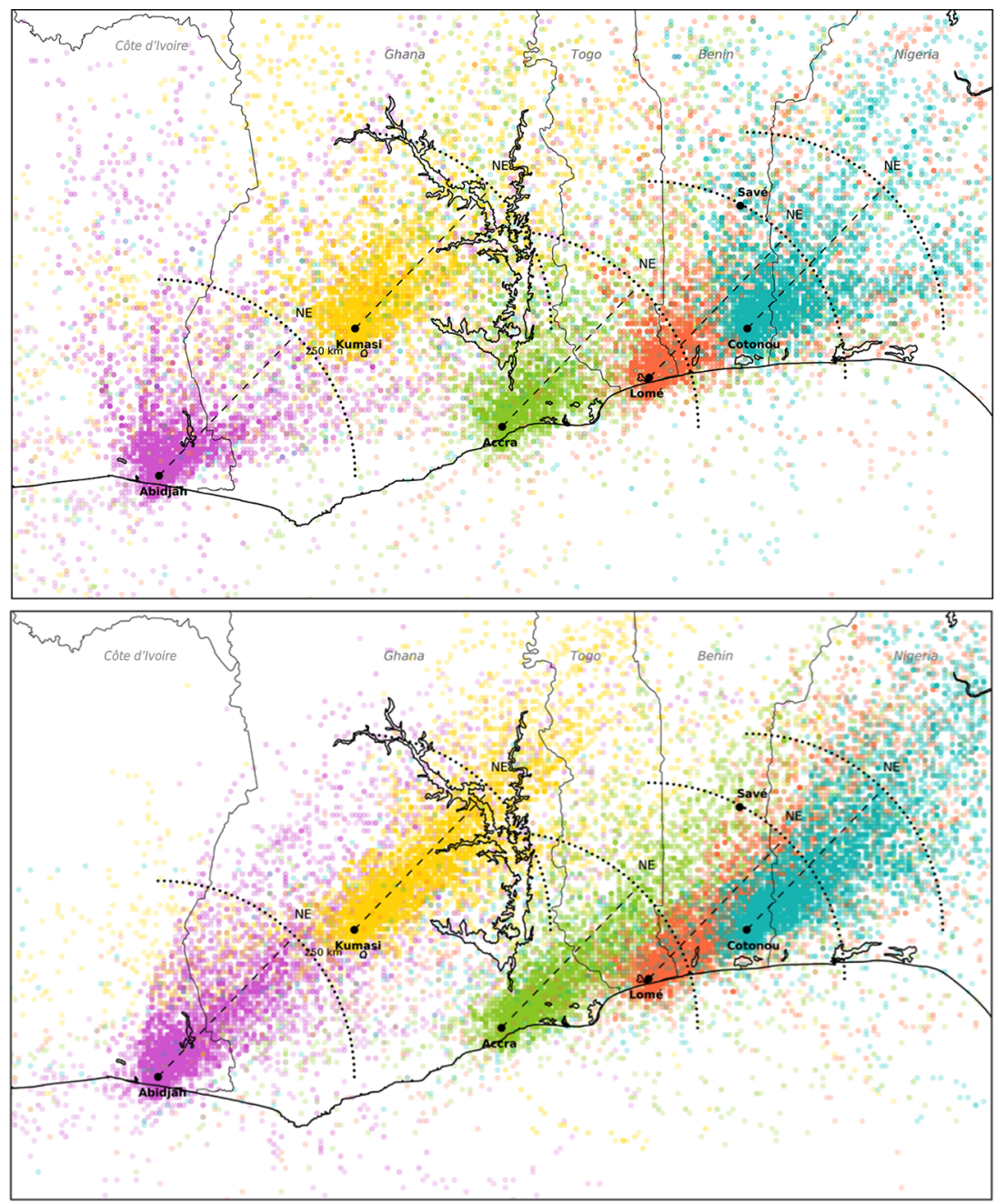

Figure 19. Pollution plumes for the five main cities of interest during DACCIWA (Abidjan, Kumasi, Accra, Lomé, Cotonou) during Phase 1 (top, 1-21 June 2016) and Phase 2 (bottom, 22 June-20 July 2016). Shown are results from daily 24 h simulations using the FLEXPART model (see Sect. 2.2). Each dot is coloured according to its city source with the opacity increasing with the occurrences of pollution tracers at each point location. The quarter circles show distances of $250 \mathrm{~km}$ around the main dispersion direction towards the northeast (dashed line).

tablished, pollution dispersion is more local and mostly directed into north- to eastward directions. During Phase 2, plumes are more clearly concentrated around the northeastward direction and stretch over long distances. Given the geographical distribution of the cities, Lomé and Cotonou are likely impacted by emissions from Accra during Phase 2, and Kumasi is likely impacted by emissions from Abidjan. Evidently quite remote areas can be affected by pollution from coastal cities in relatively short time. The supersite in Savé for example, is close to the main Accra and Lomé pollution plumes. Whether these upwind plumes actually degrade air quality in receptor cities requires further exploration using ground-based and aircraft measurements from the DACCIWA field campaign. During the 5-day period of Phase 3, due to the increased westerlies between the cyclonic and anticyclonic centres $I_{1}$ and $I_{2}$ (Fig. 16), the dominant direc- tion shifted from northeast to east-northeast, while Phase 4 is more similar to Phase 2 (not shown).

Figure 20 summarises the results for Phase 2 in the form of pollution roses for both models, giving some estimate for typical uncertainties in the dispersion estimates. As expected, the dominant transport direction is northeastward for both models and all cities, but some details clearly differ. For example, a considerable fraction is transported eastnortheastward for Accra in the HYSPLIT simulations and north-northeastward for Abidjan in FLEXPART. City pollution plumes generally reach a distance of around $300 \mathrm{~km}$ from the source point over the course of the $24 \mathrm{~h}$ simulations, with the exception of shorter plumes from Abidjan $(\sim 200 \mathrm{~km})$ in the FLEXPART simulations. 

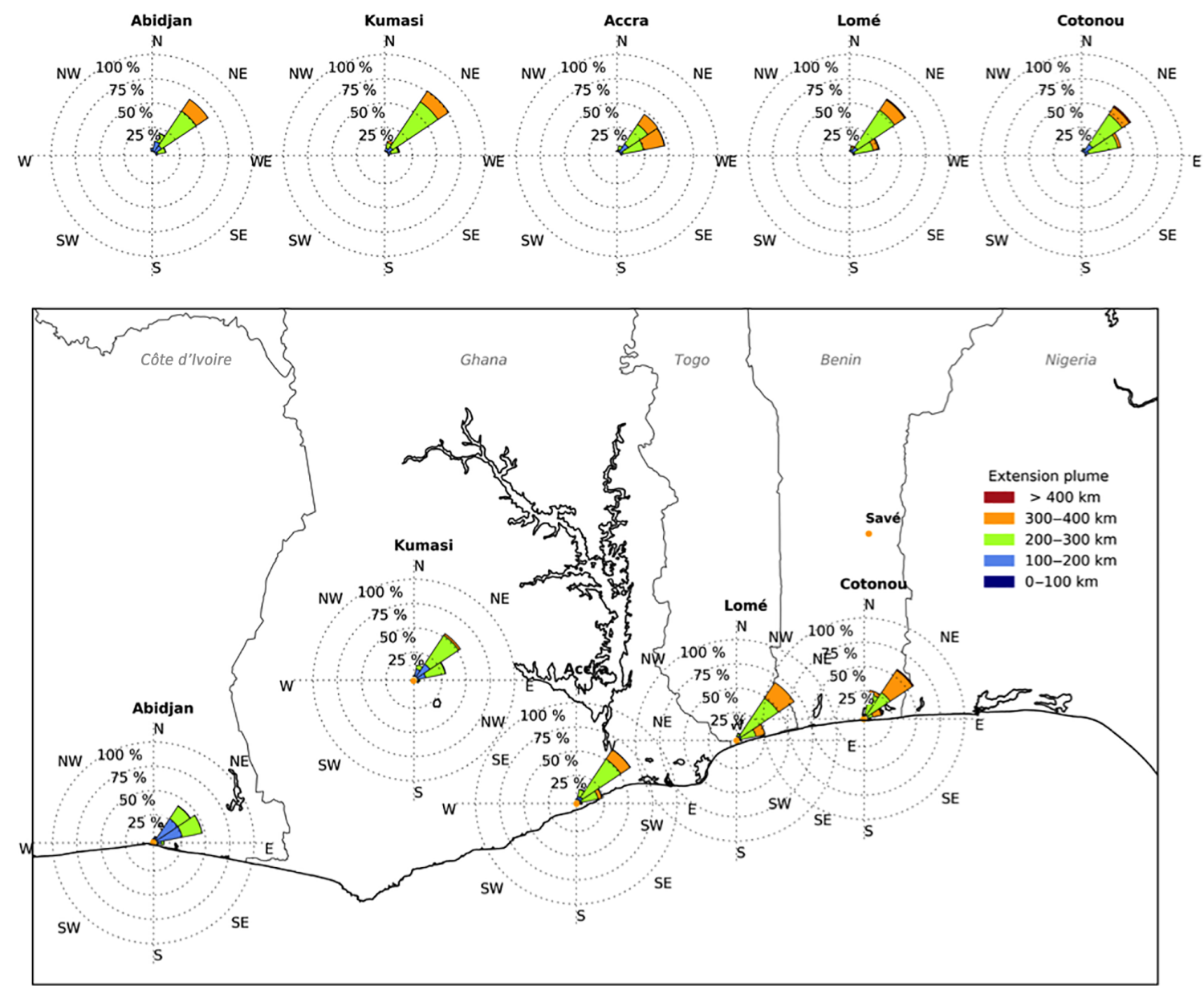

Figure 20. Pollution roses of urban plumes from the five main cities of interest during DACCIWA (Abidjan, Kumasi, Accra, Lomé, Cotonou) during Phase 2 (22 June-20 July 2016). Each rose shows the predominant direction of plumes and their horizontal extension (colour code). The radius values correspond to the percentage of pollution plume direction occurrence in each sector. Pollution roses derived from FLEXPART simulations are superimposed on the map. HYSPLIT-derived pollution roses are at the top. See Sect. 2.2 for more details.

\section{Conclusions}

Atmospheric variability over West Africa in summer is controlled by a wide range of different factors reaching from global SST patterns to local convection. Here we analysed these factors and their interplay exemplarily for the period of the main DACCIWA field campaign, i.e. June-July 2016, on the basis of ECMWF model products and satellite and radiosonde data. The DACCIWA campaign fell into a period of Pacific La Niña and Atlantic El Niño conditions, which statistically have opposing effects on Sahel rainfall. Mediterranean and Indian Ocean SSTs pointed towards a wetter than normal Sahel, but most likely the relatively warm SSTs in the tropical Atlantic dominated and led to near-normal rainfalls across the whole of West Africa during 2016.

In order to better characterise the observed changes on a day-to-day basis, objective analysis of tropical wave features and tracking of long-lived MCSs were used together with a subjective tracking of vortices in $850 \mathrm{hPa}$ streamlines. A summary of the latter is provided in Table 1. This analysis shed new light on the richness of synoptic-scale features affecting the region and their impacts on wind, precipitation, cloudiness, and the distribution of dust and biomass burning plumes. It serves as valuable background information for the more detailed examinations of the comprehensive dataset collected during the DACCIWA campaign from ground stations, aircraft, radiosondes, and satellites and as inspiration for a deeper analysis of the under-researched propagating synoptic systems of SWA and their dynamics. The 2-month DACCIWA period can be divided into four distinct phases:

- Phase 1 (1-21 June 2016): this period is characterised by pre-onset conditions with the rainfall maximum close to the Guinea coast. The ACT becomes established in the course of this period, but coastal upwelling is still weak. The SHL is relatively intense with large east-west fluctuations, also accompanied by large variations in AEJ speed. Three relatively weak westward- 
propagating vortices (A, B and $\mathrm{C}$ ) affect the region, which are associated with TDs and long-lived MCSs, creating marked variations in precipitation. Typical coverage with low clouds over SWA during this phase is about $60 \%$. Mineral dust from the Sahara and Sahel penetrates far south and occasionally reaches the coast in significant concentrations, while at the same time high values of $\mathrm{CO}$, used here as an indicator of biomass burning activity, push inland from the south. The weaker monsoon flow leads to less pollution dispersion from coastal cities. Towards the end of the phase, strong influences from the extratropics occur in the form of a deep trough and cold surge over the western Sahara around 17 June 2016, leading to a collapse of the SHL and AEJ. A cyclonic disturbance (labelled D) with two centres develops, creating an area of strong, dry, dusty northerlies to the west, followed by a deep penetration of southerlies and re-moistening of the area, which finally creates the monsoon onset. This period is also characterised by a conspicuous absence of tropical wave features.

- Phase 2 (22 June-20 July 2016): the post-onset Phase 2 is characterised by a gradual re-intensification and westward shift in the SHL with an AEJ close to climatological position and speed for most of the period. The rainfall maximum has permanently shifted inland with an anomalously dry Guinea coastal region. Rainfalls and AEJ speed are modulated by five significant synopticscale features E-I. While the first three show characteristics of classical AEWs, the latter two consist of a northern cyclonic centre and a southern anticyclonic centre. For Feature H, the anticyclonic centre is shifted eastward and slowly moves north from the SH, bringing with it a shallow layer of dry air filled with aged aerosol. For Feature I, the anticyclonic centre has an origin over central Africa and is more aligned meridionally with its cyclonic counterpart. Together they create a more westerly near-surface flow accompanied by peaks in coastal upwelling. During Phase 2, low-cloud cover over SWA generally increases to about $85 \%$. Mineral dust retreats to the Sahel and Sudanian zones with clear modulations by the major synoptic-scale features, while CO fields show a marked peak around 2 July 2016 and then weaker values afterwards. Pollution dispersion from coastal cities is stronger and mostly towards northnortheast or northeast.

- Phase 3 (21-26 July 2016): the transition between Phases 2 and 3 is accompanied by a moderate coldair intrusion into northeastern Africa. This is associated with a second breakdown of the SHL and a northward shift in and weakening of the AEJ. The short Phase 3 itself is then characterised by overall wet conditions stretching from the tropical Atlantic into the southern Sahara, with a maximum in the coastal zone. The main reason for this appears to be the moisture transport associated with the strong westerly flow between the cyclonic and anticyclonic centres of Feature I already starting in Phase 2. One further cyclonic feature $(\mathrm{J})$ occurs during this period and modulates wind and rainfall. Notably, the wet Phase 3 is almost dust-free, but high column loadings of CO penetrate deep into SWA. Pollution dispersion from coastal cities is strongest and mostly towards the northeast or even east-northeast.

- Phase 4 (27-31 July 2016): the final 5 days of the DACCIWA period are characterised by a return to more undisturbed monsoonal conditions with a more climatological SHL, AEJ and rainfall distribution. Dust, $\mathrm{CO}$ and city pollution plumes also return to conditions similar to Phase 2.

This analysis demonstrates the significant range of features affecting SWA around the period of the monsoon onset with marked impacts on cloudiness, rainfall, wind and pollution transport. Four types of behaviours can be distinguished: particularly before the onset, but also during the re-establishment of the monsoon at the end of Phase 3, single cyclonic vortices occur at different latitudes with different propagation speeds (Features A, B, C and J). These are typically related to TDs and long-lived MCSs, but the exact dynamical reason for their existence is not entire clear (see also Fig. 4 in Schrage et al., 2006, for other examples). The second type is classical AEWs with a northern and southern cyclonic vortex (Features E, F and G). These have been described extensively in the literature and their dynamics are well understood (e.g. Hall et al., 2006). They usually have a discernable signal in vorticity, wind and precipitation fields and are also objectively identified as TDs. The third type, which appears to be rarer and whose climatological and dynamical characteristics are barely covered in the literature, are jointly propagating cyclonic and anticyclonic vortices (Features $\mathrm{H}$ and I), which create an anomalous westerly flow in between them, associated with enhanced coastal upwelling and a more eastward transport of city pollution plumes. The resulting conditions appear to depend on the exact origin of the involved air masses. If the strong westerly flow taps into moist air off the west coast, where high SSTs are common, this can lead to anomalously moist conditions across the region, as has been described climatologically by Nicholson (2009) and Nicholson and Webster (2007). Handanalysed surface weather charts from Phase II of GATE show couplets of cyclonic-anticyclonic vortices, but no details are discussed (Sadler and Oda, 1979). There are some similarities with the 6-9-day wave regime described by Diedhiou et al. (1999) but the dynamical causes are not clear. Finally, extratropical influences can markedly impact weather conditions over SWA. This is usually associated with midlatitude troughs penetrating into the Sahara, cold surges and disruptions to the SHL and AEJ. During the DACCIWA period, Feature D is of particular interest, as it appears to have caused a substantial dry anomaly before the actual monsoon onset. 
Such behaviour has been described in the literature (e.g. Sultan and Janicot, 2003), but the role of the extratropics in a given year is yet to be explored, ideally also with model sensitivity experiments. Feature D is also striking since it transforms from a rather stationary low-pressure zone with several centres downstream of an extratropical trough into a westward propagating vortex couplet that is much more tropicallike and that has some resemblance to an AEW. A detailed analysis of the dynamics of this transition is beyond the scope of this study and left for future work. It is noteworthy that periods of extratropical influences appear to create the most persistent meridional flow anomalies, leading to extreme excursions of mineral dust and biomass burning plumes over SWA.

In the future, it would be desirable to study the four characteristic types of variability patterns described above in a climatological (comparing 2016 to other years) and dynamical sense. The latter could be achieved both through theoretical work on linear tropical modes taking into account the specific conditions over SWA in summer or possibly in a full non-linear sense through idealised model experiments or realistic case studies. An interesting idea to be explored further in this context is interactions between AEWs and mixed Rossby-gravity waves as suggested by Cheng et al. (2017).

Data availability. The majority of data used in this study are publicly available through third parties:

- ERA-I (Dee et al., 2011), ECMWF operational analyses and dust and CO fields from CAMS-IFS (Inness et al., 2013) can be retrieved from the ECMWF website http://www.ecmwf.int or ECMWF's Meteorological Archival and Retrieval System (MARS).

- Reynolds SST data (Reynolds et al., 2007) can be retrieved from http://www.ncdc.noaa.gov.

- TRMM product 3B42 v7 (Huffman et al., 2007) can be retrieved from https://giovanni.gsfc.nasa.gov.

- CLAAS-2 CTX and CMA products (Stengel et al., 2013; Finkensieper et al., 2016) can be found at https://doi.org/doi: 10.5676/EUM_SAF_CM/CLAAS/V002.

- SEVIRI OLR data (Schmetz et al., 2002) can be accessed via https://www.eumetsat.int/website/home/Data/ MeteosatServices/0DegreeService.

- Dispersion of city plumes based on HYSPLIT using GDAS winds is described at http://www.ready.noaa.gov.

The only data used that are original to DACCIWA are the high-resolution radiosonde measurements from Abidjan. These are available from the DACCIWA database at http://baobab.sedoo. fr/Data-Search/?datsId=1656\&project_name=DACCIWA. They do not have a DOI yet. At lower, standard TEMP resolution, they are available via https://www.ncdc.noaa.gov/data-access/ weather-balloon/integrated-global-radiosonde-archive.

\section{The Supplement related to this article is available online at https://doi.org/10.5194/acp-17-10893-2017- supplement.}

Competing interests. The authors declare that they have no conflict of interest.

Acknowledgements. The DACCIWA project has received funding from the European Union Seventh Framework Programme (FP7/2007-2013) under grant agreement no. 603502. AS has been supported from subproject " $\mathrm{C} 2$ - Prediction of wet and dry periods of the West African monsoon" of the Transregional Collaborative Research Center SFB-TR 165 "Waves to Weather" funded by the German Research Foundation (DFG), MG by the LABEX project funded by Agence Nationale de la Recherche (French National Research Agency, grant ANR-10-LABX-18-01), and TB by BMBF grant no. 01LP1520D (MIKLIP-PROMISA). The authors gratefully acknowledge the NOAA Air Resources Laboratory (ARL) for the provision of the HYSPLIT transport and dispersion model and READY website (http://www.ready.noaa.gov) used in this publication. The AERIS/SEDOO data infrastructure provided access to the GIRAFE/FLEXPART simulations, CAMS-IFS forecasts and data used in this study (http://www.aeris-data.fr and http://dacciwa.sedoo.fr). The GIRAFE/FLEXPART simulations were provided by Alain Fontaine (SEDOO). The authors would also like to thank Gregor Pante for help with producing Figs. 12 and 15, Robert Redl for his development of the AEJ detection tool, and Serge Janicot and Thierry Lefort for their effort to carefully review this paper and for their constructive criticism.

The article processing charges for this open-access publication were covered by a research centre of the Helmholtz Association.

Edited by: Anna Jones

Reviewed by: Serge Janicot and Thierry Lefort

\section{References}

Berry, G., Thorncroft, C., and Hewson, T.: African Easterly Waves during 2004 - Analysis using objective techniques, Mon. Weather Rev., 135, 1251-1267, https://doi.org/10.1175/MWR3343.1, 2007.

Birch, C. E., Parker, D. J., Marsham, J. H., Copsey, D., and GarciaCarreras, L.: A seamless assessment of the role of convection in the water cycle of the West African Monsoon, J. Geophys. Res., 119, 2890-2912, https://doi.org/10.1002/2013JD020887, 2014.

Caniaux, G., Giordani, H., Redelsperger, J. L., Guichard, F., Key, E., and Wade, M.: Coupling between the Atlantic cold tongue and the West African monsoon in boreal spring and summer, J. Geophys. Res., 116, C04003, https://doi.org/10.1029/2010JC006570, 2011.

Chauvin, F., Roehrig, R., and Lafore, J. P.: Intraseasonal variability of the Saharan heat low and its link with midlatitudes, J. Climate, 23, 2544-2561, https://doi.org/10.1175/2010JCLI3093.1, 2010. 
Chen, T. C.: Maintenance of the midtropospheric North African summer circulation: Saharan high and African easterly jet, J. Climate, 18, 2943-2962, https://doi.org/10.1175/JCLI3446.1, 2005.

Cheng, Y.-M., Thorncroft, C. D., and Kiladis, G. N.: A survey of synoptic waves over West Africa, EGU General Assembly, Vienna, Austria, 23-28 April 2017, EGU2017-11491, 2017.

Chiapello, I.: Dust Observations and Climatology, in: Mineral Dust: A Key Player in the Earth System, edited by: Knippertz, P. and Stuut, J.-B. W., Springer Netherlands, Dordrecht, 149-177, 2014.

Cook, K. H.: Generation of the African easterly jet and its role in determining West African precipitation, J. Climate, $12, \quad 1165-1184$, https://doi.org/10.1175/15200442(1999)012<1165:GOTAEJ>2.0.CO;2, 1999.

Cook, K. H.: Role of inertial instability in the West African monsoon jump, J. Geophys. Res.-Atmos., 120, 3085-3102, https://doi.org/10.1002/2014JD022579, 2015.

Dee, D. P., Uppala, S. M., Simmons, A. J., Berrisford, P., Poli, P., Kobayashi, S., Andrae, U., Balmaseda, M. A., Balsamo, G., Bauer, P., Bechtold, P., Beljaars, A. C. M., van de Berg, L., Bidlot, J., Bormann, N., Delsol, C., Dragani, R., Fuentes, M., Geer, A. J., Haimberger, L., Healy, S. B., Hersbach, H., Hólm, E. V., Isaksen, L., Kållberg, P., Kall, Köhler, M., Matricardi, M., McNally, A. P., Monge-Sanz, B. M., Morcrette, J. J., Park, B. K., Peubey, C., de Rosnay, P., Tavolato, C., Thépaut, J. N., and Vitart, F.: The ERA-Interim reanalysis: Configuration and performance of the data assimilation system, Q. J. Roy. Meteor. Soc., 137, 553-597, https://doi.org/10.1002/qj.828, 2011.

Diatta, S. and Fink, A. H.: Statistical relationship between remote climate indices and West African monsoon variability, Int. J. Climatol., 34, 3348-3367, https://doi.org/10.1002/joc.3912, 2014.

Diedhiou, A., Janicot, S., Viltard, A., De Felice, P., and Laurent, H.: Easterly wave regimes and associated convection over West Africa and tropical Atlantic: Results from the NCEP/NCAR and ECMWF reanalyses, Clim. Dynam., 15, 795822, https://doi.org/10.1007/s003820050316, 1999.

Fink, A. H. and Reiner, A.: Spatiotemporal variability of the relation between African Easterly Waves and West African Squall Lines in 1998 and 1999, J. Geophys. Res., 108, 4332, https://doi.org/10.1029/2002JD002816, 2003.

Fink, A. H., Vincent, D. G., and Ermert, V.: Rainfall types in the West African Sudanian zone during the summer monsoon 2002, Mon. Weather Rev., 134, 2143-2164, https://doi.org/10.1175/MWR3182.1, 2006.

Fink, A. H., Paeth, H., Ermert, V., Pohle, S., and Diederich, M.: Meteorological processes influencing the weather and climate of Benin, in: Impacts of Global Change on the Hydrological Cycle in West and Northwest Africa, edited by: Speth, P., Christoph, M., Diekkrüger, B., Bollig, M., Fink, A. H., Goldbach, H., Heckelei, T., Menz, G., Reichert, B., and Rössler, M., Springer, 135$149,2010$.

Finkensieper, S., Meirink, J.-F., van Zadelhoff, G.-J., Hanschmann, T., Benas, N., Stengel, M., Fuchs, P., Hollmann, R., and Werscheck, M.: CLAAS-2: CM SAF CLoud property dAtAset using SEVIRI - Edition 2, Satellite Application Facility on Climate Monitoring, https://doi.org/10.5676/EUM_SAF_CM/CLAAS/V002, 2016.

Fitzpatrick, R. G. J., Bain, C. L., Knippertz, P., Marsham, J. H., and Parker, D. J.: The West African monsoon onset: A concise comparison of definitions, J. Climate, 28, 8673-8694, https://doi.org/10.1175/JCLI-D-15-0265.1, 2015.

Fitzpatrick, R. G. J., Bain, C. L., Knippertz, P., Marsham, J. H., and Parker, D. J.: On what scale can we predict the agronomic onset of the West African Monsoon?, Mon. Weather Rev., 144, 15711589, https://doi.org/10.1175/MWR-D-15-0274.1, 2016.

Flamant, C., Knippertz, P., Fink, A. H., Akpo, A., Brooks, B., Chiu, C. J., Coe, H., Danuor, S., Evans, M., Jegede, O., Kalthoff, N., Konaré, A., Liousse, C., Lohou, F., Mari, C., Schlager, H., Schwarzenboeck, A., Adler, B., Amekudzi, L., Aryee, J., Ayoola, M., Batenburg, A. M., Bessardon, G., Borrmann, S., Brito, J., Bower, K., Burnet, F., Catoire, V., Colomb, A., Denjean, C., Fosu-Amankwah, K., Hill, P. G., Lee, J., Lothon, M., Maranan, M., Marsham, J., Meynadier, R., Ngamini, J.-B., Rosenberg, P., Sauer, D., Smith, V., Stratmann, G., Taylor, J. W., Voigt, C., and Yoboué, V.: The Dynamics-Aerosol-Chemistry-Cloud Interactions in West Africa field campaign: Overview and research highlights, B. Am. Meteorol. Soc., https://doi.org/10.1175/BAMS-D16-0256.1, online first, 2017.

Fontaine, B., Garcia-Serrano, J., Roucou, P., Rodriguez-Fonseca, B., Losada, T., Chauvin, F., Gervois, S., Sijikumar, S., Ruti, P., and Janicot, S.: Impacts of warm and cold situations in the Mediterranean basins on the West African monsoon: Observed connection patterns (1979-2006) and climate simulations, Clim. Dynam., 35, 95-114, https://doi.org/10.1007/s00382-009-05993, 2010 .

Fontaine, B., Gaetani, M., Ullmann, A., and Roucou, P.: Time evolution of observed July-September sea surface temperature-Sahel climate teleconnection with removed quasiglobal effect (1900-2008), J. Geophys. Res., 116, D04105, https://doi.org/10.1029/2010JD014843, 2011.

Gaetani, M., Fontaine, B., Roucou, P., and Baldi, M.: Influence of the Mediterranean Sea on the West African monsoon: Intraseasonal variability in numerical simulations, J. Geophys. Res., 115, D24115, https://doi.org/10.1029/2010JD014436, 2010.

Garcia-Carreras, L., Marsham, J. H., Parker, D. J., Bain, C. L., Milton, S., Saci, A., Salah-Ferroudj, M., Ouchene, B., and Washington, R.: The impact of convective cold pool outflows on model biases in the Sahara, Geophys. Res. Lett., 40, 1647-1652, https://doi.org/10.1002/grl.50239, 2013.

Garcia-Carreras, L., Parker, D. J., Marsham, J. H., Rosenberg, P. D., Brooks, I. M., Lock, A. P., Marenco, F., McQuaid, J. B., and Hobby, M.: The turbulent structure and diurnal growth of the Saharan atmospheric boundary layer, J. Atmos. Sci., 72, 693-713, https://doi.org/10.1175/JAS-D-13-0384.1, 2015.

Gu, G., Adler, R. F., Huffman, G. J., and Curtis, S.: African easterly waves and their association with precipitation, J. Geophys. Res. 109, D04101, https://doi.org/10.1029/2003JD003967, 2004.

Hall, N. M. J., Kiladis, G. N., and Thorncroft, C. D.: Threedimensional structure and dynamics of African easterly waves. Part II: Dynamical modes. J. Atmos. Sci., 63, 2231-2245, https://doi.org/10.1175/JAS3742.1, 2006.

Huffman, G. J., Bolvin, D. T., Nelkin, E. J., Wolff, D. B., Adler, R. F., Gu, G., Hong, Y., Bowman, K. P., and Stocker, E. F.: The TRMM Multisatellite Precipitation Analysis (TMPA): Quasi-global, multiyear, combined-sensor precipitation estimates at fine scales, J. Hydrometeorol., 8, 38-55, https://doi.org/10.1175/JHM560.1, 2007. 
Inness, A., Baier, F., Benedetti, A., Bouarar, I., Chabrillat, S., Clark, H., Clerbaux, C., Coheur, P., Engelen, R. J., Errera, Q., Flemming, J., George, M., Granier, C., Hadji-Lazaro, J., Huijnen, V., Hurtmans, D., Jones, L., Kaiser, J. W., Kapsomenakis, J., Lefever, K., Leitão, J., Razinger, M., Richter, A., Schultz, M. G., Simmons, A. J., Suttie, M., Stein, O., Thépaut, J.-N., Thouret, V., Vrekoussis, M., Zerefos, C., and the MACC team: The MACC reanalysis: an $8 \mathrm{yr}$ data set of atmospheric composition, Atmos. Chem. Phys., 13, 4073-4109, https://doi.org/10.5194/acp13-4073-2013, 2013.

Janicot, S., Thorncroft, C. D., Ali, A., Asencio, N., Berry, G., Bock, O., Bourles, B., Caniaux, G., Chauvin, F., Deme, A., Kergoat, L., Lafore, J.-P., Lavaysse, C., Lebel, T., Marticorena, B., Mounier, F., Nedelec, P., Redelsperger, J.-L., Ravegnani, F., Reeves, C. E., Roca, R., de Rosnay, P., Schlager, H., Sultan, B., Tomasini, M., Ulanovsky, A., and ACMAD forecasters team: Large-scale overview of the summer monsoon over West Africa during the AMMA field experiment in 2006, Ann. Geophys., 26, 2569-2595, https://doi.org/10.5194/angeo-26-25692008, 2008.

Janicot, S., Caniaux, G., Chauvin, F., De Coëtlogon, G., Fontaine, B., Hall, N., Kiladis, G., Lafore, J. P., Lavaysse, C., Lavender, S. L., Leroux, S., Marteau, R., Mounier, F., Philippon, N., Roehrig, R., Sultan, B., and Taylor, C. M.: Intraseasonal variability of the West African monsoon, Atmos. Sci. Lett., 12, 58-66, https://doi.org/10.1002/asl.280, 2011.

Joly, M. and Voldoire, A.: Influence of ENSO on the West African monsoon: Temporal aspects and atmospheric processes, J. Climate, 22, 3193-3210, https://doi.org/10.1175/2008JCLI2450.1, 2009.

Kiladis, G. N., Thorncroft, C. D., and Hall, N. M. J.: Three-dimensional structure and dynamics of African easterly waves. Part I: Observations, J. Atmos. Sci., 63, 2212-2230, https://doi.org/10.1175/JAS3741.1, 2006.

Knippertz, P., Coe, H., Chiu, J. C., Evans, M. J., Fink, A. H., Kalthoff, N., Liousse, C., Mari, C., Allan, R. P., Brooks, B., Danour, S., Flamant, C., Jegede, O. O., Lohou, F., and Marsham, J. H.: The DACCIWA project: Dynamics-aerosolchemistry-cloud interactions in West Africa, B. Am. Meteorol. Soc., 96, 1451-1460, https://doi.org/10.1175/BAMS-D-1400108.1, 2015a.

Knippertz, P., Evans, M. J., Field, P. R., Fink, A. H., Liousse, C., and Marsham, J. H.: The possible role of local air pollution in climate change in West Africa, Nature Climate Change, 5, 815822, https://doi.org/10.1038/nclimate2727, 2015b.

Kuettner, J. P.: General description and central program of GATE, B. Am. Meteorol. Soc., 55, 712-719, 1974.

Lafore, J. P., Flamant, C., Giraud, V., Guichard, F., Knippertz, P., Mahfouf, J. F., Mascart, P., and Williams, E. R.: Introduction to the AMMA Special Issue on "Advances in understanding atmospheric processes over West Africa through the AMMA field campaign", Q. J. Roy. Meteor. Soc., 136, 2-7, https://doi.org/10.1002/qj.583, 2010.

Lavaysse, C., Flamant, C., Janicot, S., Parker, D. J., Lafore, J. P., Sultan, B., and Pelon, J.: Seasonal evolution of the West African heat low: A climatological perspective, Clim. Dynam., 33, 313330, https://doi.org/10.1007/s00382-009-0553-4, 2009.

Lavaysse, C., Flamant, C., Janicot, S., and Knippertz, P.: Links between African easterly waves, midlatitude circulation and intraseasonal pulsations of the West African heat low, Q. J. Roy. Meteor. Soc., 136, 141-158, https://doi.org/10.1002/qj.555, 2010a.

Lavaysse, C., Flamant, C., and Janicot, S.: Regional-scale convection patterns during strong and weak phases of the Saharan heat low, Atmos. Sci. Lett., 11, 255-264, https://doi.org/10.1002/asl.284, 2010b.

Lebel, T., Parker, D. J., Flamant, C., Bourlès, B., Marticorena, B., Mougin, E., Peugeot, C., Diedhiou, A., Haywood, J. M., Ngamini, J. B., Polcher, J., Redelsperger, J. L., and Thorncroft, C. D.: The AMMA field campaigns: Multiscale and multidisciplinary observations in the West African region, Q. J. Roy. Meteor. Soc., 136, 8-33, https://doi.org/10.1002/qj.486, 2010.

Lélé, M. I. and Lamb, P. J.: Variability of the Intertropical Front (ITF) and rainfall over the West African Sudan-Sahel zone, J. Climate, 23, 3984-4004, https://doi.org/10.1175/2010JCLI3277.1, 2010.

Lindzen, R. S. and Nigam, S.: On the role of sea surface temperature gradients in forcing low-level winds and convergence in the tropics, J. Atmos. Sci., 44, 2418-2436, 1987.

Liousse, C., Assamoi, E., Criqui, P., Granier, C., and Rosset, R.: Explosive growth in African combustion emissions from 2005 to 2030, Environ. Res. Lett., 9, 35003, https://doi.org/10.1088/1748-9326/9/3/035003, 2014.

Losada, T., Rodríguez-Fonseca, B., Janicot, S., Gervois, S., Chauvin, F., and Ruti, P.: A multi-model approach to the Atlantic Equatorial mode: Impact on the West African monsoon, Clim. Dynam., 35, 29-43, https://doi.org/10.1007/s00382-009-0625-5, 2010.

Mari, C. H., Cailley, G., Corre, L., Saunois, M., Attié, J. L., Thouret, V., and Stohl, A.: Tracing biomass burning plumes from the Southern Hemisphere during the AMMA 2006 wet season experiment, Atmos. Chem. Phys., 8, 3951-3961, https://doi.org/10.5194/acp-8-3951-2008, 2008.

Mari, C. H., Reeves, C. E., Law, K. S., Ancellet, G., AndrésHernández, M. D., Barret, B., Bechara, J., Borbon, A., Bouarar, I., Cairo, F., Commane, R., Delon, C., Evans, M. J., Fierli, F., Floquet, C., Galy-Lacaux, C., Heard, D. E., Homan, C. D., Ingham, T., Larsen, N., Lewis, A. C., Liousse, C., Murphy, J. G., Orlandi, E., Oram, D. E., Saunois, M., Serça, D., Stewart, D. J., Stone, D., Thouret, V., van Velthoven, P., and Williams, J. E.: Atmospheric composition of West Africa: Highlights from the AMMA international program, Atmos. Sci. Lett., 12, 13-18, https://doi.org/10.1002/asl.289, 2011.

Marsham, J. H., Dixon, N. S., Garcia-Carreras, L., Lister, G. M. S., Parker, D. J., Knippertz, P., and Birch, C. E.: The role of moist convection in the West African monsoon system: Insights from continental-scale convection-permitting simulations, Geophys. Res. Lett., 40, 1843-1849, https://doi.org/10.1002/grl.50347, 2013.

Mathon, V. and Laurent, H.: Life cycle of Sahelian mesoscale convective cloud systems, Q. J. Roy. Meteor. Soc., 127, 377-406, https://doi.org/10.1002/qj.49712757208, 2001.

Mohino, E., Rodríguez-Fonseca, B., Mechoso, C. R., Gervois, S., Ruti, P., and Chauvin, F.: Impacts of the tropical Pacific/Indian Oceans on the seasonal cycle of the West African monsoon, J. Climate, 24, 3878-3891, https://doi.org/10.1175/2011JCLI3988.1, 2011. 
Mohino, E., Janicot, S., Douville, H., and Li, L. Z. X.: Impact of the Indian part of the summer MJO on West Africa using nudged climate simulations, Clim. Dynam., 38, 2319-2334, https://doi.org/10.1007/s00382-011-1206-y, 2012.

Mounier, F., Janicot, S., and Kiladis, G. N.: The West African monsoon dynamics. Part III: The quasi-biweekly zonal dipole, J. Climate, 21, 1911-1928, https://doi.org/10.1175/2007JCLI1706.1, 2008.

Nicholson, S. E.: On the factors modulating the intensity of the tropical rainbelt over West Africa, Int. J. Climatol., 29, 673-689, https://doi.org/10.1002/joc.1702, 2009.

Nicholson, S. E. and Webster, P. J.: A physical basis for the interannual variability of rainfall in the Sahel, Q. J. Roy. Meteor. Soc., 133, 2065-2084, https://doi.org/10.1002/qj.104, 2007.

Nnamchi, H. C. and Li, J.: Influence of the South Atlantic Ocean dipole on West African summer precipitation, J. Climate, 24, 1184-1197, https://doi.org/10.1175/2010JCLI3668.1, 2011.

Okumura, Y. and Xie, S.: Some overlooked features of tropical Atlantic climate leading to a new Niño-like phenomenon, J. Climate, 19, 5859-5874, https://doi.org/10.1175/JCLI3928.1, 2006.

Park, J., Bader, J., and Matei, D.: Anthropogenic Mediterranean warming essential driver for present and future Sahel rainfall, Nature Climate Change, 6, 941-945, https://doi.org/10.1038/nclimate3065, 2016.

Pohl, B., Janicot, S., Fontaine, B., and Marteau, R.: Implication of the Madden-Julian oscillation in the 40-day variability of the West African monsoon, J. Climate, 22, 3769-3785, https://doi.org/10.1175/2009JCLI2805.1, 2009.

Polo, I., Rodríguez-Fonseca, B., Losada, T., and García-Serrano, J.: Tropical atlantic variability modes (1979-2002). Part I: Timeevolving SST modes related to West African rainfall, J. Climate, 21, 6457-6475, https://doi.org/10.1175/2008JCLI2607.1, 2008.

Redelsperger, J.-L., Thorncroft, C. D., Diedhiou, A., Lebel, T., Parker, D. J., and Polcher, J.: African Monsoon Multidisciplinary Analysis - An international research project and field campaign, B. Am. Meteorol. Soc., 87, 1739-1746, https://doi.org/10.1175/BAMS-87-12-1739, 2006.

Reynolds, R. W., Smith, T. M., Liu, C., Chelton, D. B., Casey, K. S., and Schlax, M. G.: Daily high-resolution-blended analyses for sea surface temperature, J. Climate, 20, 5473-5496, https://doi.org/10.1175/2007JCLI1824.1, 2007.

Rodríguez-Fonseca, B., Mohino, E., Mechoso, C. R., Caminade, C., Biasutti, M., Gaetani, M., Garcia-Serrano, J., Vizy, E. K., Cook, K., Xue, Y., Polo, I., Losada, T., Druyan, L., Fontaine, B., Bader, J., Doblas-Reyes, F. J., Goddard, L., Janicot, S., Arribas, A., Lau, W., Colman, A., Vellinga, M., Rowell, D. P., Kucharski, F., and Voldoire, A.: Variability and predictability of West African droughts: A review on the role of sea surface temperature anomalies, J. Climate, 28, 4034-4060, https://doi.org/10.1175/JCLI-D14-00130.1, 2015.

Roehrig, R., Chauvin, F., and Lafore, J. P.: 10-25-day intraseasonal variability of convection over the Sahel: A role of the Saharan heat low and midlatitudes, J. Climate, 24, 5863-5878, https://doi.org/10.1175/2011JCLI3960.1, 2011.

Roundy, P. E. and Frank, W. M.: A climatology of waves in the equatorial region, J. Atmos. Sci., 61, 2105-2132, https://doi.org/10.1175/15200469(2004)061<2105:ACOWIT>2.0.CO;2, 2004.
Rowell, D. P.: Teleconnections between the tropical Pacific and the Sahel, Q. J. Roy. Meteor. Soc., 127, 1683-1706, https://doi.org/10.1002/qj.49712757512, 2001.

Rowell, D. P.: Simulating SST teleconnections to Africa: What is the state of the art?, J. Climate, 26, 5397-5418, https://doi.org/10.1175/JCLI-D-12-00761.1, 2013.

Ryder, C. L., McQuaid, J. B., Flamant, C., Rosenberg, P. D., Washington, R., Brindley, H. E., Highwood, E. J., Marsham, J. H., Parker, D. J., Todd, M. C., Banks, J. R., Brooke, J. K., Engelstaedter, S., Estelles, V., Formenti, P., Garcia-Carreras, L., Kocha, C., Marenco, F., Sodemann, H., Allen, C. J. T., Bourdon, A., Bart, M., Cavazos-Guerra, C., Chevaillier, S., Crosier, J., Darbyshire, E., Dean, A. R., Dorsey, J. R., Kent, J., O’Sullivan, D., Schepanski, K., Szpek, K., Trembath, J., and Woolley, A.: Advances in understanding mineral dust and boundary layer processes over the Sahara from Fennec aircraft observations, Atmos. Chem. Phys., 15, 8479-8520, https://doi.org/10.5194/acp15-8479-2015, 2015.

Sadler, J. C. and Oda, L. K.: The synoptic (A) scale circulations during the second phase of GATE, 17 July-19 August 1974, UHMET 78-02, Dept. Meteor., University of Hawaii, 41 pp., 1979.

Schmetz, J., Pili, P., Tjemkes, S., Just, D., Kerkmann, J., Rota, S., and Ratier, A.: An introduction to Meteosat Second Generation (MSG), B. Am. Meteorol. Soc., 83, 977-992, https://doi.org/10.1175/15200477(2002)083<0977:AITMSG>2.3.CO;2, 2002.

Schrage, J. M., Fink, A. H., Ermert, V., and Ahlonsou, E. D.: Three MCS cases occurring in different synoptic environments in the sub-Sahelian wet zone during the 2002 West African monsoon, J. Atmos. Sci., 63, 2369-2382, https://doi.org/10.1175/JAS3757.1, 2006.

Schröder, M., König, M., and Schmetz, J.: Deep convection observed by the Spinning Enhanced Visible and Infrared Imager on board Meteosat 8: Spatial distribution and temporal evolution over Africa in summer and winter 2006, J. Geophys. Res., 114, D05109, https://doi.org/10.1029/2008JD010653, 2009.

Shao, Y., Wyrwoll, K. H., Chappell, A., Huang, J., Lin, Z., McTainsh, G. H., Mikami, M., Tanaka, T. Y., Wang, $X$., and Yoon, S.: Dust cycle: An emerging core theme in Earth system science, Aeolian Research, 2, 181-204, https://doi.org/10.1016/j.aeolia.2011.02.001, 2011.

Skinner, C. B. and Diffenbaugh, N. S.: The contribution of African easterly waves to monsoon precipitation in the CMIP3 ensemble, J. Geophys. Res.-Atmos., 118, 3590-3609, https://doi.org/10.1002/jgrd.50363, 2013.

Stein, A. F., Draxler, R. R., Rolph, G. D., Stunder, B. J. B., Cohen, M. D., and Ngan, F.: NOAA's HYSPLIT atmospheric transport and dispersion modeling system, B. Am. Meteorol. Soc., 96, 2059-2077, https://doi.org/10.1175/BAMS-D-14$00110.1,2015$.

Stengel, M., Kniffka, A., Meirink, J. F., Riihelä, A., Trentmann, J., Müller, R., Lockhoff, M., and Hollmann, R.: CLAAS: CM SAF CLoud property dAtAset using SEVIRI - Edition 1 - Hourly/Daily Means, Pentad Means, Monthly Means/Monthly Mean Diurnal Cycle/Monthly Histograms, Satellite Application Facility on Climate Monitoring (CM SAF), https://doi.org/10.5676/EUM_SAF_CM/CLAAS/V001, 2013.

Stohl, A., Forster, C., Frank, A., Seibert, P., and Wotawa, G.: Technical note: The Lagrangian particle dispersion model 
FLEXPART version 6.2, Atmos. Chem. Phys., 5, 2461-2474, https://doi.org/10.5194/acp-5-2461-2005, 2005.

Sultan, B. and Janicot, S.: The West African monsoon dynamics. Part II: The "preonset" and "onset" of the summer monsoon, J. Climate, 16, 3407-3427, https://doi.org/10.1175/15200442(2003)016<3407:TWAMDP>2.0.CO;2, 2003.

Thorncroft, C. D. and Blackburn, M.: Maintenance of the African easterly jet, Q. J. Roy. Meteor. Soc., 125, 763-786, https://doi.org/10.1002/qj.49712555502, 1999.

Thorncroft, C. D. and Hoskins, B. J.: An idealized study of African easterly waves. I: A linear view, Q. J. Roy. Meteor. Soc., 120, 953-982, https://doi.org/10.1002/qj.49712051809, 1994a.

Thorncroft, C. D. and Hoskins, B. J.: An idealized study of African easterly waves. II: A nonlinear view, Q. J. Roy. Meteor. Soc., 120, 983-1015, https://doi.org/10.1002/qj.49712051810, 1994b.

Ting, M., Kushnir, Y., Seager, R., and Li, C.: Robust features of Atlantic multi-decadal variability and its climate impacts, Geophys. Res. Lett., 38, L17705, https://doi.org/10.1029/2011GL048712, 2011.

Todd, M. C., Allen, C. J. T., Bart, M., Bechir, M., Bentefouet, J., Brooks, B. J., Cavazos-Guerra, C., Clovis, T., Deyane, S., Dieh, M., Engelstaedter, S., Flamant, C., Garcia-Carreras, L., Gandega, A., Gascoyne, M., Hobby, M., Kocha, C., Lavaysse, C., Marsham, J. H., Martins, J. V., McQuaid, J. B., Ngamini, J. B., Parker, D. J., Podvin, T., Rocha-Lima, A., Traore, S., Wang, Y., and Washington, R.: Meteorological and dust aerosol conditions over the western Saharan region observed at Fennec Supersite-2 during the intensive observation period in June 2011, J. Geophys. Res.-Atmos., 118, 8426-8447, https://doi.org/10.1002/jgrd.50470, 2013.

van der Linden, R., Fink, A. H., and Redl, R.: Satellite-based climatology of low-level continental clouds in southern West Africa during the summer monsoon season, J. Geophys. Res., 120, 1186-1201, https://doi.org/10.1002/2014JD022614, 2015.

Vizy, E. K. and Cook, K. H.: A mechanism for African monsoon breaks: Mediterranean cold air surges, J. Geophys. Res., 114, D01104, https://doi.org/10.1029/2008JD010654, 2009.
Wallace, J. M., Mitchell, T. P., and Deser, C.: The influence of sea-surface temperature on surface wind in the eastern equatorial Pacific: Seasonal and interannual variability, J. Climate, 2, 1492-1499, https://doi.org/10.1175/15200442(1989)002<1492:TIOSST>2.0.CO;2, 1989.

Wheeler, M. and Kiladis, G. N.: Convectively coupled equatorial waves: Analysis of clouds and temperature in the wavenumber-frequency domain, J. Atmos. Sci., 56, 374-399, https://doi.org/10.1175/15200469(1999)056<0374:CCEWAO>2.0.CO;2, 1999.

Williams, M. and Houze, R. A.: Satellite-observed characteristics of winter monsoon cloud clusters, Mon. Weather Rev., 115, 505-519, https://doi.org/10.1175/15200493(1987)115<0505:SOCOWM>2.0.CO;2, 1987.

Wu, M. L. C., Reale, O., Schubert, S. D., Suarez, M. J., Koster, R. D., and Pegion, P. J.: African easterly jet: Structure and maintenance, J. Climate, 22, 4459-4480, https://doi.org/10.1175/2009JCLI2584.1, 2009.

Wu, M. L. C., Reale, O., Schubert, S. D., Suarez, M. J., and Thorncroft, C. D.: African easterly jet: Barotropic instability, waves, and cyclogenesis, J. Climate, 25, 1489-1510, https://doi.org/10.1175/2011JCLI4241.1, 2012.

Zhang, R. and Delworth, T. L.: Impact of Atlantic multidecadal oscillations on India/Sahel rainfall and Atlantic hurricanes, Geophys. Res. Lett., 33, L17712, https://doi.org/10.1029/2006GL026267, 2006. 